\title{
PERFORMANCE OF REVERSE LOGISTICS IN ELECTRONIC COMMERCE: A CASE STUDY FROM LEBANON AND SYRIA
}

\author{
Vida DAVIDAVIČIENE் $\dot{E}^{*}$ Mohamad AL MAJZOUB \\ Dept of Business Technologies and Entrepreneurship, Vilnius Gediminas Technical University, Lithuania \\ Submitted 2 June 2020; resubmitted 8 January 2021, 18 March 2021; accepted 7 April 2021; \\ first published online 21 May 2021
}

\begin{abstract}
The technological advancements facilitated the progress of the Business-To-Consumer (B2C) e-commerce business tremendously. B2C e-commerce has several benefits such as saving costs by decreasing the use of resources, increasing profits, and competitive advantage, especially in the pandemic context. However, this opportunity comes with challenges, and one of such is related to a significant number of products that are returned to the vendor or manufacturer. These challenges in the Reverse Logistics' (RL) in the context of e-commerce become a new phenomenon - Reverse E-Logistics' (REL), because the product in the e-commerce is physical goods or electronic ones like videos, music, books, etc. This study focuses on identifying the most critical factors that impact REL performance and discusses how REL can affect its performance. The methodology used is mainly a literature review, synthesis, survey methods, and Structural Equation Modelling (SEM). This study is done in Lebanon and Syria with a sample of 412 companies that perform B2C e-commerce and are faced with REL'. The results showed that out of the ten factors identified during the literature review, eight factors (management, employees, IT and technology, return policy and procedures/guarantee, infrastructure, organizational structure and culture, customer services/satisfaction, and quality management) have a positive correlation with REL performance. Moreover, improved REL performance results increase in companies' performances. The business research model was created based on performed REL performance in Lebanon and Syria, and this gives new scientific insights and knowledge about REL specificity in developing countries.
\end{abstract}

Keywords: reverse logistics, e-logistics, e-commerce, reverse e-logistics, reverse e-logistics' performance, supply chain, performance measurement.

\section{Notations}

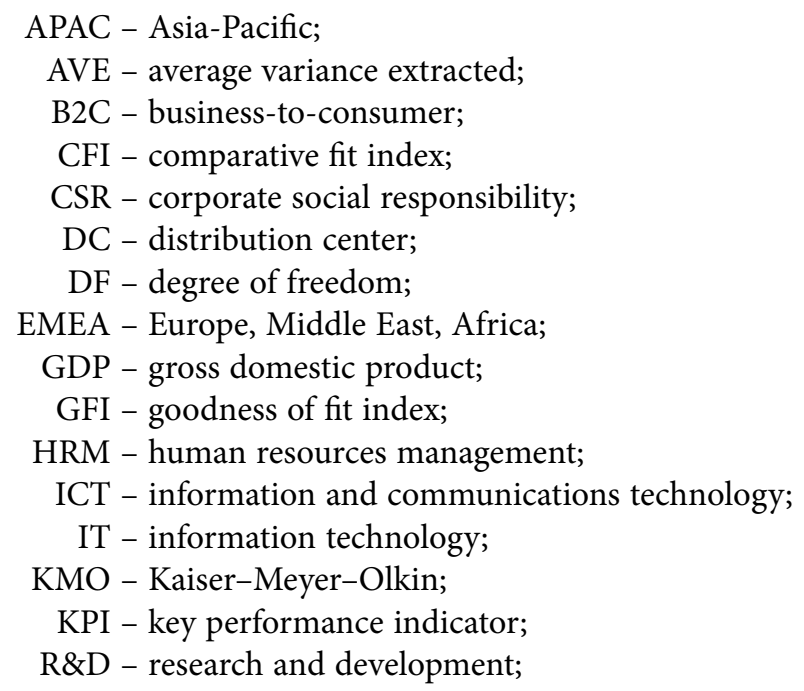


et al. 2020). REL refers to the reverse flow of materials through the maximization of their value using online platforms (Han, Trimi 2018). REL activities comprise gathering, examination and categorization, disposition (reutilization, overhaul, remanufacture, recycle), and relocation of returned goods (Agrawal et al. 2016). When implemented correctly, REL gathers numerous benefits, such as increased profits, customer satisfaction, and resources' efficiency (Han, Trimi 2018). REL is considered as a tactical instrument for B2C e-commerce firms since it allows those firms to have a potent competitive advantage manifested by a good corporate image, consumers' loyalty, and a better competing position (Al Majzoub, Davidavičienè 2019). However, neglecting the importance of REL and its effective management could cause financial loss of the company as well as the loss of market share or image determination of the company. REL' costs are from 9.5 up to $50 \%$ in certain industries (Pandian, Abdul-Kader 2017). The returned products, due to defection and other causes, reach between $\$ 800$ million to $\$ 1$ billion in online marketplaces, and the returned products' costs for retailers was about $\$ 260$ billion in 2016 (Morgan et al. 2018). About $10 \%$ of online transactions' costs are attributed to one of the following: returned goods, annulment, and repayment entitlements (Tavengerwei 2018). Returned products represent more than $35 \%$ of the total e-commerce retailers' cost (Huang et al. 2015). The B2C e-commerce increase returns from sales by 1.35 times more than brickand-mortar businesses (Chen et al. 2016). Different regions have different opportunities for REL. Nevertheless, among the top regions in the APAC area, including the Middle East, which recorded an increase of $23 \%$ in B2C e-commerce utilization (Xu et al. 2016). Thus, creating opportunities for established and existing firms to consider this area more and to invest in it. Globally, $70 \%$ of B2C ecommerce firms are subjected to at least one serious problem in their supply chain and REL systems (Ghasemzadeh et al. 2017). In 2016, there were more than 2.5 billion B2C e-commerce consumers in the world, yielding on average $\$ 2671$ billion, among which is $\$ 1057$ billion contributed APAC region and the Middle East, giving it a top position among other regions (Choi, Mai 2018). In 2015, the costs of REL' were about $\$ 130.6$ billion and $\$ 223.6$ billion for APAC and EMEA regions, respectively. Measuring and improving the performance of REL is highly complicated, complex, and difficult (Shaik, Abdul-Kader 2018; Sudarto et al. 2017; Han, Trimi 2018; Agrawa et al. 2016; Euchi et al. 2019), and this is often neglected. This created a deficiency in the academic research, especially in empirical ones, on the performance's evaluation and major factors affecting RL (Sangwan 2017; Vlachos 2016; Huang et al. 2015). Studies of REL in the developing countries, and precisely in the Middle East, are very few. Moreover, till today this field awaits solutions to enhance the REL performance (Euchi et al. 2019; Panigrahi et al. 2018; Agarwal et al. 2016; Prakash, Barua 2015).

Thus, the objective of this study is to identify the most important factors that affect the effective implementation of REL, and to determine REL performance impact on the company's performance. This resulted research questions:

"» RQ1: What are the most important factors that are directly correlated with REL performance, and to what extent do these factors impact it?;

"» RQ2: Does the REL performance positively correlated with companies' performance?

The methods used in this study are literature review, synthesis, comparison analysis, survey methods, and SEM.

\section{Review of literature}

\subsection{REL concept specifics}

$\mathrm{RL}$ refers to the procedure focused on the management of returned goods awaiting recovery via processes such as: reusing, fixing, recycling, or awaiting complete disposal (Euchi et al. 2019). RL is segmented into five key activities: first is concerning the inputs manifested by production's factors and inventory's forecasting; second is the processes explained by dismantling products, putting procedures for returning goods, management, infrastructure, production's capabilities, and all the remaining constituents of the supply chain; third is the structure, which is related to the planning of location and distribution channels; fourth is the outputs that is done by explicitly stating the prices, having good competition, and information about services; fifth is the social and organization activities by making sure that diverse stakeholders are satisfied, including third parties logistics, in addition to clear return policies and effective decision-making (Pulansari et al. 2016). Several authors in RL field defined it in different terms summarized in Table 1.

From RL the REL concept has emerged. REL is the ICT enabled RL. REL refers to performing RL' processes but electronically or online. REL is the reverse flow of goods from the point of consumption to the point of production has in the middle an e-commerce vendor (Morgan et al. 2018). REL is the branch in logistics that deals with goods sold in e-commerce returning, reducing resources' utilization through effective management of recycling, waste discarding, restoring, and remanufacturing (Mahindroo et al. 2018). REL is responsible for maintaining effective and efficient supply chain systems for e-commerce companies. In other words, focusing on the reverse flow of materials represents the objective of REL through the maximization of the supply chain's value (Han, Trimi 2018). However, designing REL varies from forwarding logistics to reverse ones. A set of activities included in the forward logistics, such as converting raw materials into finished goods, aren't necessarily found in REL' processes (Vlachos 2016). The principal differences between both types of logistics rely on the qualities of products, transportation, in addition to the packaging and pricing (Sangwan 2017). The purpose of REL is to make the return of products easier to the business cycle to which economic, environmental, and legal services are added. Main REL's definition is summarized in Table 2. 
Table 1. Main definitions of RL (source: compiled by authors)

\begin{tabular}{|l|l|}
\hline \multicolumn{1}{|c|}{ Definition of RL } & \multicolumn{1}{c|}{ Source } \\
\hline $\begin{array}{l}\text { RL entitles all relevant procedures for returning after-sale and after-consumption products for } \\
\text { the purpose of productive recycling, utilizing reversed distribution channels. }\end{array}$ & Chileshe et al. (2018) \\
\hline $\begin{array}{l}\text { RL refers to the assembly of damaged or unutilized goods from retail stores. It includes diverse } \\
\text { procedures of the supply chain, but in a reversed direction, that is from consumers to producers. }\end{array}$ & Panigrahi et al. (2018) \\
\hline $\begin{array}{l}\text { RL is defined as planning, implementing, and modifying the stream of raw materials from users } \\
\text { to producers in order to assemble or dispose of goods. }\end{array}$ & Sirisawat, Kiatcharoenpol (2018) \\
\hline $\begin{array}{l}\text { RL summarizes all procedures related to goods' recovery, such as: restoring, recycling, } \\
\text { reproducing, and discarding. }\end{array}$ & Tosarkani, Amin (2018) \\
\hline
\end{tabular}

Table 2. Main definitions of REL (source: compiled by authors)

\begin{tabular}{|l|l|}
\hline \multicolumn{1}{|c|}{ Definition of REL } & \multicolumn{1}{|c|}{ Source } \\
\hline $\begin{array}{l}\text { The inverse stream of products and information from consumption's location to original location } \\
\text { with the help of different ICT systems. }\end{array}$ & Morgan et al. (2018) \\
\hline $\begin{array}{l}\text { Electronically locating goods' movement from customers' consumption point to the } \\
\text { manufacturers' origin point. }\end{array}$ & Pandian, Abdul-Kader (2017) \\
\hline E-management of materials' flows based on evaluating their effective performance. & Cannella et al. (2016) \\
\hline
\end{tabular}
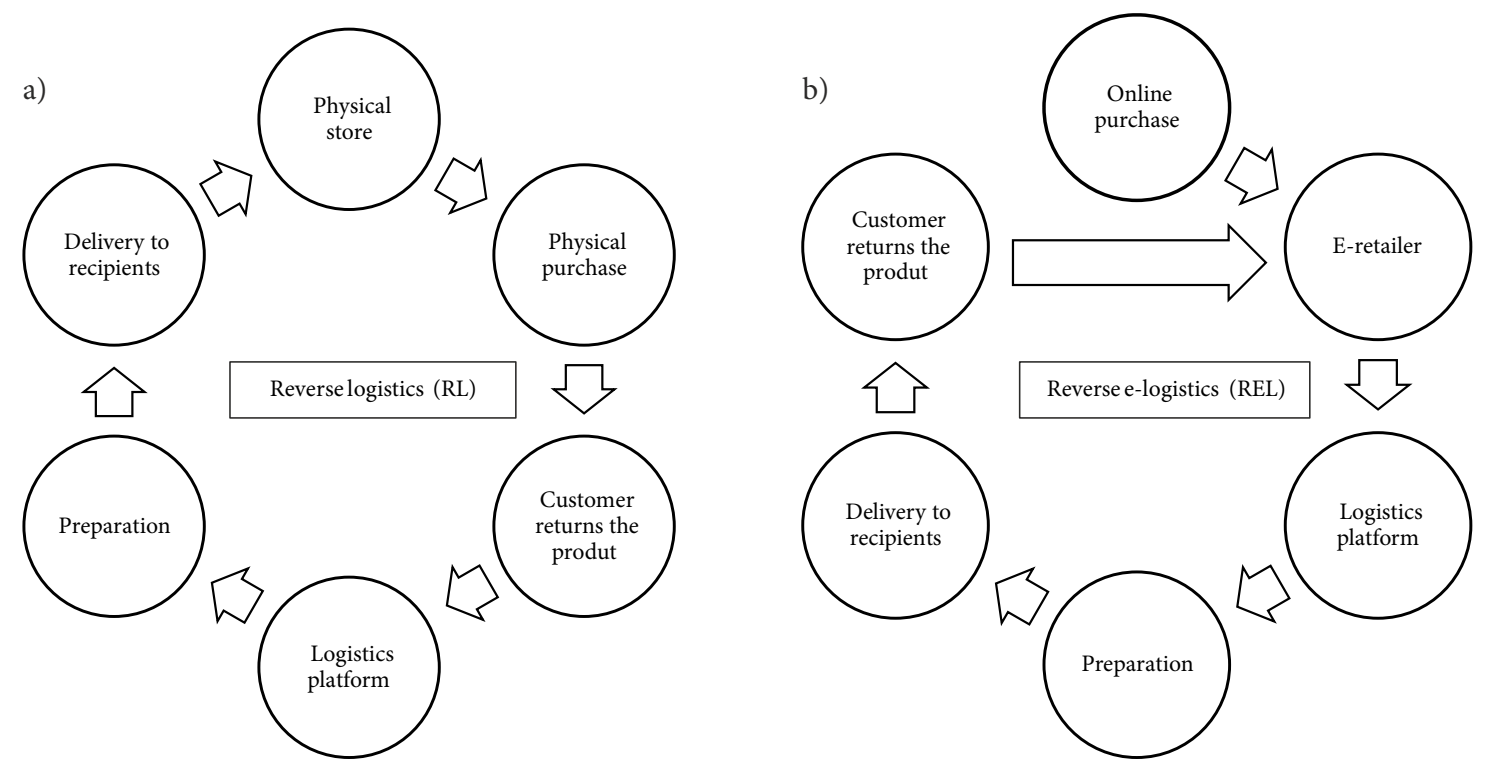

Figure 1. Difference between RL (a) and REL (b) (source: compiled by authors)

It is stated that the REL can lead to the strategical and operational recapture of economic value more than RL, which offers services with added values to diminish risks and improve the e-business image (Da Silveira Guimarães, Salomon 2015). Briefly, REL is the new and most used model of RL. The main differences between RL and REL is depicted in Figure 1.

REL's has significant benefits when implemented correctly. For instance, REL performance decreases costs and increases profits (Xu et al. 2015; Chen et al. 2016; Agarwal et al. 2016; Ardila Gamboa, Ballesteros Riveros 2018; Euchi et al. 2019; Huang et al. 2015; Sri Yogi 2015; Han, Trimi 2018; Tosarkani, Amin 2018; Li et al. 2018), increases customer satisfaction (Bouzon et al. 2015; Pham, Ahammad 2017; Nisar, Prabhakar 2017; Han, Trimi 2018; Huang et al. 2015; Mahindroo et al. 2018; Vlachos 2016;
Panigrahi et al. 2018; Da Silveira Guimarães, Salomon 2015) and enhances the efficiency of resources' utilization (Agarwal et al. 2016; Sirisawat, Kiatcharoenpol 2018; Vlachos 2016; Sun 2017; Yu, Solvang 2017; Chileshe et al. 2018). The main purpose of REL is to maximize the value of returned products (Han, Trimi 2018). REL is the summation of diverse processes such as preparation, implementing, and regulating the flow of raw materials, inventory, and finished products, efficiently from the customer to the manufacturer in order to recollect products or dispose of them (Sirisawat, Kiatcharoenpol 2018). REL could also have other objectives such as recycling, repairing, reusing, reproducing, as well as restoration (Yu, Solvang 2017). Moreover, REL comprises activities associated with product recoveries such as acquisition, dismantling, re-advertising, and refabrication (Tosarkani, Amin 2018). 
REL activities include two main classifications and the first is related to returning products from consumers to manufacturers due to bad customer satisfaction, defected goods, or wrong products, whereas the second one is strictly aimed for recycling and recovery purposes (Batarfi et al. 2017). REL is a step-by-step process by which the products, materials, and miscellaneous resources are assembled from consumers to get them back to the manufacturer in a profitable manner (Ardila Gamboa, Ballesteros Riveros 2018). REL comprises four key functions: assembly, classification/trying, withdrawal, and redeploying (Sangwan 2017). Certain organizations sum REL processes into four: landfilling, recovering, remanufacturing, and reprocessing (Chinda 2017). REL manages the recovery of goods after attaining their end-life time periods (Batarfi et al. 2017). REL ensures that scheduling, implementing, and controlling the movement of materials are done efficiently and effectively (Sri Yogi 2015). REL processes strive to make returning of goods from the point of consumption more easy and convenient by adding to the financial, ecological, and legitimate services a strong value (Tseng, Hung 2014). REL events encompass assembly, inspection, classification, and transfer of returned products (Agrawal et al. 2016). REL involves not only monitoring but also evaluating the effectiveness of products' flow activities from consumers to producers (Pandian, Abdul-Kader 2017).

Understanding the basic components of REL and its systems enable a firm to understand its operations more and to distinguish it from other activities that might have things in common, but they are not alike. A firm striving to enhance REL performance must first understand the factors that are indispensable to the success of REL systems, and the review of literature analysis helped in determining the basic understanding of REL systems. There-

Table 3. Main findings in REL field (source: compiled by authors)

\begin{tabular}{|c|c|}
\hline Source & Main findings of the study \\
\hline $\begin{array}{l}\text { Euchi et al. } \\
\text { (2019) }\end{array}$ & $\begin{array}{l}\text { this study, first, it was found that REL improved performance will result in better economic performance and } \\
\text { igher customer satisfaction. The two most important variables that affect customer satisfaction from REL are } \\
\text { xe dedication of staff in customer service and maintaining a good customer relationship no matter at which } \\
\text { xpense. }\end{array}$ \\
\hline $\begin{array}{l}\text { Govindan, } \\
\text { Bouzon (2018) }\end{array}$ & $\begin{array}{l}\text { total of } 36 \text { barriers were analysed to see their impact on environmental sustainability and REL performance } \\
\text { ad direct stakeholders. The most significant ones that affect REL performance are the ones from inside the firm } \\
\text { ce technology, infrastructure, profits, knowledge, policies, competitors, and management. }\end{array}$ \\
\hline $\begin{array}{l}\text { Han, Trimi } \\
(2018)\end{array}$ & $\begin{array}{l}\text { Social networks and commerce can add value to REL performance, in addition to a better CSR by protecting } \\
\text { the environmental protection by taking, for instance, end of use products to recycling processes. Among the } \\
\text { several platforms, there are four that are extremely important to enhance REL performance, which is: consumers' } \\
\text { relationship, users' comments and reviews, quality control, utilization perils. }\end{array}$ \\
\hline $\begin{array}{l}\text { Tan, Guo } \\
(2019)\end{array}$ & $\begin{array}{l}\text { The main concern of REL activities should be not only decreasing costs but should be directed to environmental } \\
\text { protection and go green concept as well. Both forward and RL should be integrated. Therefore, focusing on } \\
\text { factors that affect REL performance, those that showed to be positively correlated, are the government's rules } \\
\text { and regulations, which can improve the quality of recycling since the latter has high uncertainty and cannot be } \\
\text { determined easily. }\end{array}$ \\
\hline $\begin{array}{l}\text { Agrawal et al. } \\
(2016)\end{array}$ & $\begin{array}{l}\text { EL performance is highly dependent on the three major factors in the order of significance: economic } \\
\text { measured by creating and adding value, ROI), environmental (measured by low energy usage, ideal usage of } \\
\text { aputs), and then the social performance (measured by customers' safety, and complaints). }\end{array}$ \\
\hline $\begin{array}{l}\text { Ardila } \\
\text { Gamboa, } \\
\text { Ballesteros } \\
\text { Riveros (2018) }\end{array}$ & $\begin{array}{l}\text { Measuring the performance of DCs relying on KPI in REL. Results showed that DC with better efficiency, } \\
\text { which is measured by calculating outputs over inputs, and which have higher better relative efficiency, which } \\
\text { is measured by calculating a weighted average of outputs over the weighted Average of Inputs, have better REL } \\
\text { performances, and thus they have better profits and decision-making. }\end{array}$ \\
\hline $\begin{array}{l}\text { Bal, Satoglu } \\
(2018)\end{array}$ & $\begin{array}{l}\text { The main objective is to recover electric waster from different electronic equipment from delivering to returning } \\
\text { these products. The findings showed that in order to decrease electronic wastes, REL performance should be } \\
\text { enhanced via improvement of operations planning, resources sustainability, and legal regulations. }\end{array}$ \\
\hline $\begin{array}{l}\text { Batarfi et al. } \\
(2017)\end{array}$ & $\begin{array}{l}\text { Due to the huge progress of technology and thus e-commerce, } \mathrm{B} 2 \mathrm{C} \text { businesses are seizing the opportunities in } \\
\text { that field. However, REL cannot be neglected since returns are always expected. The main purpose is to identify } \\
\text { the importance of return policy on REL performance, and the results showed that the more reassuring and } \\
\text { generous it is, the more profits would be there. }\end{array}$ \\
\hline $\begin{array}{l}\text { Cannella et al. } \\
\text { (2016) }\end{array}$ & $\begin{array}{l}\text { The study analyses the inventory management, orders and returned-order flow in the companies. Returns are } \\
\text { sometimes for recycling objectives, which impose challenges on inventory management, and replenishments } \\
\text { should be applied. Therefore, solutions should reduce remanufacturing and order lead-time, return a proportion } \\
\text { of recycled goods, and impose a clear reverse order policy. Also, managerial implications are needed to reduce } \\
\text { costs. }\end{array}$ \\
\hline $\begin{array}{l}\text { Chileshe et al. } \\
\text { (2018) }\end{array}$ & $\begin{array}{l}\text { The value of the supply chain should be reinforced with the activities of REL. The most important aspects } \\
\text { affecting REL performance are economic (costs and quality), environmental (lowering pollution), and social } \\
\text { factors (go green). }\end{array}$ \\
\hline Chinda (2017) & $\begin{array}{l}\text { About } 17 \text { factors affect REL performance in the construction industry. The top factors that scored the highest } \\
\text { significant impacts were abiding laws and regulations, recycling encouragement, the experience of management, } \\
\text { and infrastructure. }\end{array}$ \\
\hline
\end{tabular}


fore, to better understand how REL performance can be improved, the analysis of factors that might be impacting REL performance must be performed.

REL's activities are identified and separated from other activities of the supply chain in e-commerce. Several authors discussed the new concept of REL, and they related it to the function of organizational operations. They have suggested that focusing and improving REL can be done in certain ways and result in significant improvement in the firm's performance. Table 3 summarizes the authors' main findings in REL field.

After identifying the already discovered work by authors in the field of REL, the next step is to identify a new concept and discoveries by building a novel model that helps in improving REL's performance. In order to be able to do so, the next step is to further understand what factors might be having a direct impact on REL's activities.

\subsection{Factors impacting REL performance}

Authors in the REL field-suggested several factors to be the most important ones affecting REL performance. These factors are management, quality management, organizational structure and culture, IT and technology, Customer services/satisfaction, return policy and procedures/guarantee, employees, and infrastructure. Therefore, analysis and investigation of such factors must be done in order to understand how enhancing REL performance can be achieved. Table 4 summarizes the factors mentioned with their respective authors and years.

Table 4. Factors affecting REL' performance (source: compiled by authors 2020)

\begin{tabular}{|c|c|c|c|c|c|c|c|c|c|c|}
\hline Factors & 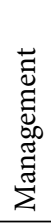 & 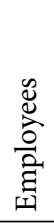 & 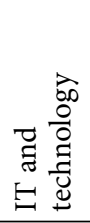 & 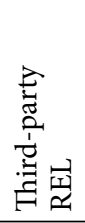 & 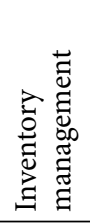 & 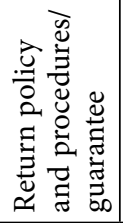 & 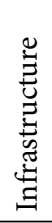 & 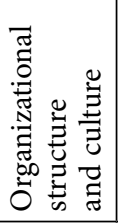 & 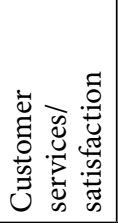 & 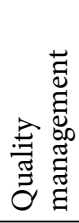 \\
\hline Sirisawat, Kiatcharoenpol (2018) & $x$ & & $x$ & & & $\times$ & $x$ & $\times$ & & $x$ \\
\hline Prakash, Barua (2015) & $x$ & & $x$ & & & $x$ & $x$ & $x$ & $x$ & $x$ \\
\hline Waqas et al. (2018) & $x$ & $x$ & $x$ & $x$ & & $x$ & $x$ & $x$ & & $x$ \\
\hline Cannella et al. (2016) & $x$ & & & & $x$ & $x$ & & $x$ & & \\
\hline Ardila Gamboa, Ballesteros Riveros (2018) & $x$ & $x$ & $x$ & & & $x$ & & $x$ & & $x$ \\
\hline Pandian, Abdul-Kader (2017) & $x$ & & & & $x$ & $x$ & & & & $x$ \\
\hline Morgan et al. (2018) & $x$ & $\times$ & $\times$ & & & $x$ & $x$ & $x$ & & $\times$ \\
\hline Huang et al. (2015) & $x$ & $x$ & $x$ & & & $x$ & & $x$ & $x$ & $x$ \\
\hline Euchi et al. (2019) & $x$ & $x$ & $x$ & & & $x$ & & & $x$ & $x$ \\
\hline Yadav, Barve (2015) & & & & & & & & $x$ & & \\
\hline Chinda (2017) & $x$ & & 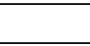 & & & & $x$ & & & \\
\hline Govindan, Bouzon (2018) & $x$ & & $x$ & & & & $x$ & & & \\
\hline Bouzon et al. (2015) & & & $x$ & & & & $x$ & & $x$ & \\
\hline Vlachos (2016) & $x$ & & $x$ & $x$ & $x$ & $x$ & & $x$ & $x$ & $x$ \\
\hline Agrawal et al. (2016) & & & & $x$ & $x$ & & & & & \\
\hline \multicolumn{11}{|l|}{ Tan, Guo (2019) } \\
\hline Han, Trimi (2018) & & & $x$ & $x$ & & & & & $x$ & \\
\hline Sirisawat, Kiatcharoenpol (2018) & $x$ & $x$ & $x$ & $x$ & & & & & & \\
\hline Da Silveira Guimarães, Salomon (2015) & & & $x$ & & & $x$ & & & & \\
\hline Mahindroo et al. (2018) & & & $x$ & & & & & & $x$ & $x$ \\
\hline Sri Yogi (2015) & & & & & $x$ & & $x$ & & $x$ & $x$ \\
\hline Bal, Satoglu (2018) & & $x$ & & & & & & & & \\
\hline Panigrahi et al. (2018) & & & & & $x$ & & & & $x$ & $x$ \\
\hline Sudarto et al. (2016) & & & & & & & & & $x$ & \\
\hline Li et al. (2018) & & & & $x$ & & & & & & \\
\hline Tosarkani, Amin (2018) & & & & $x$ & & & & & & $x$ \\
\hline \multicolumn{11}{|l|}{ Chileshe et al. (2018) } \\
\hline Batarfi et al. (2017) & & & $x$ & & & $x$ & & & $x$ & \\
\hline Sangwan (2017) & & & & $x$ & $x$ & & & & $x$ & \\
\hline Eskandarpour et al. (2014) & & & & & & & & & $x$ & \\
\hline Bai, Sarkis (2019) & & & & $x$ & & & & & & \\
\hline Wang et al. (2019) & & & & $x$ & & & & & & \\
\hline Sremac et al. (2018) & & & & $x$ & & & & & & \\
\hline Cooper et al. (2016) & & & & & & & & & $x$ & \\
\hline Daugherty et al. (2019) & & & & & & & & & $x$ & \\
\hline Ochocka (2019) & & & & & & & & & $x$ & \\
\hline Asian et al. (2019) & & & & & & & & & $x$ & \\
\hline
\end{tabular}


Management. The REL capabilities are divided into six main elements: logistics information, management, close-loop, supply chain integration and synchronization, conformity, and institutional incentives. Among these elements, management is the most significant one in terms of impacting REL performance (Vlachos 2016). The main obstacles faced by management are the absence of commitment, strategic planning, experience, knowledge, and resistance to change, even though such change might be helpful in achieving better REL performance (Sirisawat, Kiatcharoenpol 2018). Managers can affect REL activities based on three important aspects, their authority, influence, and urgency (Huang et al. 2015). The absence of interest, knowledge, awareness, and commitment by managers from different departments are considered as potent obstacles for an effective REL implementation (Waqas et al. 2018; Govindan, Bouzon 2018). Skilled employees at the production site is necessary but alone is not enough for an effective REL implementation. It should be followed by experienced and knowledgeable managers capable of making the right decisions (Chinda 2017). It is the duty of managers to know the importance of coping with change and handling any resistance when there is a need to move from traditional to updated systems since this will add value to REL activities and eventually result in a better competing position in the market (Sirisawat, Kiatcharoenpol 2018). Managers play an important role in improving REL performance, and any deficiency in managerial skills, support, planning, or even awareness of REL aspects, will lead to a decrease in REL performance (Prakash, Barua 2015). Enactment of clear guidelines whereby every employee should know his exact contribution to the good REL implementation should be stated and followed up by the experienced managers of the firm (Cannella et al. 2016). For activities of REL to be successful, a manager's job should not be restricted to one aspect only; rather the manager's efforts should be directed towards better management in quality (Ardila Gamboa, Ballesteros Riveros 2018). A firm's REL performance cannot reach the optimal level of effectiveness in the absence of managers that are experts, especially at the operational level of the supply chain (Pandian, Abdul-Kader 2017). REL managers must understand the significance of their continuous efforts for a sustainable REL performance (Morgan et al. 2018). When good managerial strategies, skills, and knowledge exist, REL activities have higher chances of success (Euchi et al. 2019).

Therefore, hypothesis 1 generated is:

"» H1: Management is positively correlated with REL performance.

Employees. Some firms producing electronic products are suffering from bad REL due to unexperienced employees (Sirisawat, Kiatcharoenpol 2018). The employees working in customer service and who are responsible for managing REL activities such as handling returned products, are very important to customer satisfaction and for a successful REL systems (Euchi et al. 2019). Empowering employees by involving them in decision-making, provid- ing proper training, increasing communication and coordination, and developing their skills all are important for having professional employees capable of handling REL activities in the firm's supply chain (Waqas et al. 2018). One of the strongest KPIs for a successful REL implementation, if not the most potent one, is the professionalism of the firm's - HRM (Ardila Gamboa, Ballesteros Riveros 2018). A sustainable supply chain, and thus a sustainable REL performance is correlated with a good HRM' performance inside the firms (Morgan et al. 2018). A good HRM cannot be established without a good relationship with all the employees working in the company (Huang et al. 2015). Maintaining the optimal number of employees for the firm's operations and its supply chain, including REL systems, should always be monitored since any decrease in the number of employees will lead to a decrease in REL performance (Bal, Satoglu 2018).

Therefore, hypothesis 2 generated is:

"» H2: Incompetent employees are negatively correlated with REL performance.

IT and technology. Technological advancement can improve REL performance significantly since it reduces the time to react and increases knowledge in managing the REL processes in a more effective way (Sirisawat, Kiatcharoenpol 2018). Social networks and commerce can add value to REL performance (Han, Trimi 2018). Due to the huge progress of technology and thus e-commerce, $\mathrm{B} 2 \mathrm{C}$ business is seizing the opportunities in that field since it is impacting positively REL activities' performance (Batarfi et al. 2017). The ideal solution for good REL implementation is to capitalize and improve REL technology since it proved to significantly impact REL performance and on the supply chain (Prakash, Barua 2015). The most important factors affecting REL implementation in an effective manner are the lack of IT systems, technology applied, and infrastructure. Therefore, as a solution, firms should capitalize more in research and development and consider outsourcing to a third-party as an alternative (Waqas et al. 2018). The readiness of precise technology and information system for REL is a key success factor for effective REL activities' implementation (Govindan, Bouzon 2018). Researchers suggested that the benefit behind updated technology and IT systems is not exclusive to REL performance but to the creativity, as well as responsiveness (Morgan et al. 2018). Crucial technologies, especially those that are protected by intellectual property, improve REL performance and decrease the costs of its diverse operations (Vlachos 2016). The utilization of updated IT systems improves coordination between employees and managers since they facilitate the information's processing making it more quick and easy, thereby improving REL performance whenever needed (Euchi et al. 2019). Actually, technological innovation can be used for the main reason to improve REL performance, yet it can be used to protect the environment by encouraging recycling at lower costs and decreasing the utilization of factors of production (Da Silveira Guimarães, Salomon 2015). Good management of the available IT system is 
a good indicator of successful REL implementation (Ardila Gamboa, Ballesteros Riveros 2018). A firm looking for a competitive advantage in its REL aspects must make sure that the updated and strong information systems are always present (Huang et al. 2015). Actually, IT systems are one of the most potent key factors affecting the performance of REL (Bouzon et al. 2015). In other words, when improvements in logistics' information system are obtained, REL performance will improve in turn (Vlachos 2016). For supply chain managers to be able to manage REL activities efficiently, especially in handling returned goods, the existence of IT systems is not negotiable (Mahindroo et al. 2018).

Therefore, hypothesis 3 generated is:

"» H3: IT is positively correlated with REL performance.

Third-party REL. Firms have to be aware of which functions of REL they should outsource to a third-party. Firms should choose to outsource those functions that it has little or no knowledge about, or in case, they have a shortage of resources or capabilities (Li et al. 2018). REL processes are really complicated, this is why firms lacking good knowledge of such activities prefer outsourcing these activities, either partially or entirely, to a third-party REL' supplier (Wang et al. 2019). The third-party REL provider must add a significant value to REL activities for the outsourcing firm, and thus this REL provider must be the best among his peers (Sirisawat, Kiatcharoenpol 2018; Bai, Sarkis 2019). Sometimes, a firm needs more than one provider to reach optimal REL performance (Tosarkani, Amin 2018). In this case, evaluating available REL thirdparty providers is a must (Vlachos 2016). Moreover, occasionally the alliance to a third-party REL provider is indispensable for effective implementation of REL activities due to its benefits ranging from decreasing costs to better customer service and satisfaction as well (Sangwan 2017; Sremac et al. 2018). Outsourcing is a great option that when implemented correctly, by choosing the optimal third-party partners, will enhance REL performance and lead to increased profits (Li et al. 2018). To enhance REL activities, emphasis should be on the party that will collect returned products (for diverse reasons), how to make use of the returned products, and finally, where to convey the recovered goods (Sangwan 2017). The effective implementation of REL can lead to protecting the environment while increasing profits at the same time. However, because of complexity in its operations, REL sometimes cannot be performed by the firm itself, thus the need for a third-party REL' providers are required (Tosarkani, Amin 2018). The company that cannot have its own transportation and distribution systems should consider a third-party to handle such activities in order to reduce their costs (Agrawal et al. 2016). Thus, the presence of a good and reliable third-party RL provider is a must (Han, Trimi 2018).

Therefore, hypothesis 4 generated is:

"» H4: Absence of effective third-party REL providers is negatively correlated with REL performance.
Inventory management. Firms must be knowledgeable and experienced in terms of managing inventories, and all its diverse aspects, from gathering goods to forecasting and handling returned goods (Sangwan 2017). If a firm chooses to operate and handle all REL activities by itself, it has to understand and manage its inventory levels with care due to its direct impact on REL performance (Vlachos 2016). In case the firm manages its inventory in a wellorganized and controlled way, then the result will be lower costs, higher profits, and customer satisfaction (Agrawal et al. 2016). One of the most complicated parts of inventory management is the ability to forecast the estimated number of products that are going to be returned and ordered. However, if the forecasting part is done correctly, then REL performance will be improved significantly (Sri Yogi 2015). In order to this, the firm should have enough knowledge and experience in controlling and managing inventories' levels (Panigrahi et al. 2018). However, sometimes returned products, for the sake of recycling, decrease the costs of raw materials. This is an advantage to the firms willing to decrease the use of resources (Cannella et al. 2016). Increasing REL performance is a must that should be done by focusing on products' fulfillment, lead time, warehousing's cost and spaces, the turnover rate of stocks, and volume tractability (Sri Yogi 2015). The most important constituent of good inventory management is the availability of good forecasting techniques that permit to predict the approximate quantity of products and to deliver them on time (Pandian, Abdul-Kader 2017).

Therefore, hypothesis 5 generated is:

"» H5: Bad inventory management is negatively correlated with REL performance.

Return policy and procedures/guarantee. Identifying the importance of return policy on REL performance is a must since they are positively correlated. Moreover, the more reassuring and generous the return policy is, the more profits will be obtained (Batarfi et al. 2017). Returns of goods are sometimes for recycling objectives, which impose challenges on inventory management and replenishments. Therefore, solutions should be on reducing remanufacturing and orders lead-time, returning a proportion of recycled goods, and imposing clear reverse order policies (Cannella et al. 2016). Having unclear return policies is the same as having no policies at all (Euchi et al. 2019). When there was a return policy, the greatest number of returned products were for laptops, mobile phones, personal computers, and televisions, respectively (Pandian, AbdulKader 2017). Uncertainty in determining the number of returns for reasons such as recycling, or disassembly, can be handled more easily in the presence of a well-detailed and communicated return policy for both consumers and employees (Sudarto et al. 2016). The scarcity and reduction of resources are growing the costs of landfills. Moreover, a good return policy for sellers should emphasize on the significance of REL for producers and further stakeholders (Waqas et al. 2018). In several nations, waste management activities cannot be entirely or partially deployed entirely 
due to the absence of a strong return policy (Govindan, Bouzon 2018). Goods might be returned for reasons such as a return policy, defective goods, wrong items delivered, or withdrawing products for the purpose of recycling. Among these reasons, the most reason that proved to be the most effective on REL performance is the return policy (Pandian, Abdul-Kader 2017). A firm's return policy should be focusing on decreasing the number of returns, but sometimes the existence of such policy ends in increasing the returned products (Sirisawat, Kiatcharoenpol 2018). Firms must acquire and communicate a strong return policy that is able to handle and sort all returned goods according to their most convenient paths, whether recycle or remanufacture, in an attempt to increase their values (Prakash, Barua 2015). Policy on returned products should not be exclusive to defective products, but it should be inclusive to other purposes such as recycling, and disassembly, as well (Waqas et al. 2018). An increase in sales is dependent on a good REL performance, which is directly affected by a clear, well-explained, and detailed return policy that is communicated to both employees and customers (Ardila Gamboa, Ballesteros Riveros 2018). A firms' sustainability policy cannot be done without a policy concerning returned goods (Morgan et al. 2018). Thus, a strong return management processes should exist for such a purpose (Huang et al. 2015). To enhance the terms of a return policy, ensuring the value recovery of returned goods, and offering policies better than the market's competitors, become a must (Da Silveira Guimarães, Salomon 2015). However, it is important to pay attention that due to the high and changing needs of customers, and because it is important to have a return policy, the number of returned goods might increase as a result of such policy (Vlachos 2016). Among the most important factors for effective implementation of REL is the guarantee (Pandian, Abdul-Kader 2017). The presence of a guarantee will lead to a kind of reassurance for the buyers to purchase the product (Euchi et al. 2019). However, at the same time, the guarantee might lead to a higher number of returned products, and it directly impacts the performance of REL (Huang et al. 2015). Due to its importance and its effect on REL performance and sales, guarantee nowadays is made as an integral part of not only REL activities, but the supply chain as a whole (Sri Yogi 2015; Panigrahi et al. 2018). Consumers might return goods due to various reasons, among which are: returns for recycling, disassembly, disposal, defects, and guarantee for product life cycle (Tosarkani, Amin 2018).

Therefore, hypothesis 6 generated is:

"» H6: Absence of return policy and procedures/guarantee are negatively correlated with REL performance.

Infrastructure. Infrastructure affecting REL is either internal, referring to everything in the firm starting from warehouses' technology and spaces, vehicles used for transportation, forecasting and controlling returns using updated equipment (Sirisawat, Kiatcharoenpol 2018), or it could refer to external meaning outside the firm, such as road structures and conditions, internet connections' speed, and safety measures taken for B2C e-commerce users (Prakash, Barua 2015). An organization with bad infrastructure means that this organization has a bad REL performance, bad returns' management, and bad profits (Sirisawat, Kiatcharoenpol 2018; Prakash, Barua 2015; Sri Yogi 2015; Govindan, Bouzon 2018; Morgan et al. 2018). Thus a firm that is aiming to enhance its REL performance should start enhancing its infrastructure, since the latter does not only impact REL, but the firm's supply chain as a whole (Morgan et al. 2018; Govindan, Bouzon 2018). However, sometimes the problem of bad infrastructure is not related to the firm itself, that is it is not internal, rather it is related to the country where it operates, and this creates serious issues. For instance, most of the developing countries, including those in the Middle East, suffer from bad infrastructure in the internet, roads, water, and electricity, and this incurred firms operating there with high costs, thereby eventually closing their businesses in these regions (Bouzon et al. 2015). This is why those firms neglect such countries to work in when they do their feasibility studies. Therefore, governments of such countries should have a potent infrastructure to encourage B2C e-commerce there as well (Sri Yogi 2015). The absence of strong and updated infrastructure creates huge obstacles for B2C e-commerce companies (Waqas et al. 2018). The deficiency of retrieval amenities, infrastructure, and conventional-used resources markets prevent the effective implementation of REL activities (Chinda 2017).

Therefore, hypothesis 7 generated is:

"» H7: Infrastructure is positively correlated with REL performance.

Organizational structure and culture. Researches in the field of REL performance showed that the first and most important factor that affects its performance is the effective and flexible organizational structure (Yadav, Barve 2015). REL performance is directly linked to a good organizational structure that understands the basic needs of its employees, operations, and capacities (Morgan et al. 2018; Cannella et al. 2016). Thus if a firm has a suitable organizational structure, the REL performance will be enhanced (Sirisawat, Kiatcharoenpol 2018). However, to answer the question of to what extent can the organizational structure affects REL performance is a matter of a firm's philosophy, policies, principles, coordination, and level of formality or informality inside the firm per se (Waqas et al. 2018). The most significant factors that impact the performance of the supply chain and RL during disasters are the organizational structure and the government policies in that field (Yadav, Barve 2015). A well-developed, coherent, and effective organizational structure will give the firms a competitive advantage and make huge changes in terms of increasing profits (Prakash, Barua 2015). Firms' structures can change ineffective REL activities to effective REL, in case an optimal structure is found (Waqas et al. 2018). The bad organizational culture in a firm, which 
could be highly contributed to the presence of bad management, will result in a bad REL performance (Waqas et al. 2018). In order to solve any problem that might face the implementation of REL practices, the firm's policies and guidelines set play an important role in prioritizing the most important factors for REL activities (Sirisawat, Kiatcharoenpol 2018). The organizational culture that will develop policies for forwarding supply chain movement without taking into consideration the RL as well will not have the expected results (Cannella et al. 2016). The firm's managers and top managers are responsible for creating a supportive culture in order to have effective REL systems capable of overcoming any unpredicted obstacles. A firm lacking a supportive culture is a firm that wants bad REL performance (Prakash, Barua 2015). Among the top factors affecting REL performance, if not the most potent one, is the presence of a culture that is able to make REL a successful one (Ardila Gamboa, Ballesteros Riveros 2018). Encouraging a sustainability culture in terms of resources, management, and responsibilities, facilitate reaching the objectives of REL practices (Morgan et al. 2018). A good REL performance is found in a good organizational performance is found which is highly dependent on a cultural system and policies inside the organization (Huang et al. 2015). Having a culture that supports coordination and communication first between the employees and second between the firm and its suppliers, make the process of profits' increasing an easier one (Vlachos 2016).

Therefore, hypothesis 8 generated is:

"» H8: Organizational structures and cultures are positively correlated with REL performance.

Customer services/satisfaction. Customer service refers to all the activities related to providing the customers with the product in an efficient and effective way that yields and maintains customer satisfaction (Cooper et al. 2016). Good customer service means a reasonable customer satisfaction, and this will result in improved REL performance. In addition to all of these benefits, effective customer service will yield better sales and more profits (Vlachos 2016; Euchi et al. 2019; Sudarto et al. 2016; Daugherty et al. 2019). However, good customer service cannot be separated from inventory management since any unavailable product will result in bad service (Sri Yogi 2015). The greatest challenge that customer service imposes is the fact that different customers have different needs and demands. Therefore, B2C e-commerce firms should be aware of such facts and satisfy the needs of these customers accordingly (Ochocka 2019). In case of returning a product by the customer, whether a defective product or for any other reason, the customer awaits a fast, immediate, and effective service (Asian et al. 2019). The two most important variables that affect customer satisfaction from REL are the dedication of staff in customer service and maintaining a good customer relationship (Euchi et al. 2019). The optimal network system is the one that deals with everything in handling and returning a product through a seven steps process, starting from pri- mary consumers, assembly/redistribution hubs, retrieval, recycling and discarding hubs, to secondary consumers (Eskandarpour et al. 2014). The main factors affecting REL performance in terms of customer satisfaction are motivation, costs, adding value, consumer behavior, supply chain management, return policies (impact consumer retention), retailing, networks' capabilities, and knowledge (Panigrahi et al. 2018). The intention of contributing to the welfare of not only shareholders but also towards consumers will yield higher customer satisfaction and thus higher consumer loyalty (Bouzon et al. 2015). A good, differentiated, and long-term customer service is also manifested by after-sales service, and a service that takes B2C e-consumers into consideration will impact REL activities positively (Da Silveira Guimarães, Salomon 2015). A dual benefit relationship exists from an improved REL performance, which are: improved decision-making processes and increased customer satisfaction (Sri Yogi 2015). When REL activities are effective, this indicates the imminent effectiveness in the reduction of expenses and increase in profits and customer satisfaction, thereby creating a potent competitive advantage in the market (Huang et al. 2015). Firms should understand the importance of having satisfied customers since this satisfaction will give loyalty, and this is an opportunity to increase profits that should not be missed (Prakash, Barua 2015). The successful implementation of REL system is crucial to improve customer satisfaction and firm's performance. However, the measurement criteria and standards are still limited (Han, Trimi 2018). Stressing on diverse REL activities such as managing returned products, keeping the customers informed, and taking their feedback into consideration, are all important aspects to ensure fair and continuous customers' satisfaction (Mahindroo et al. 2018). Handling the returned products is a challenging activity for the firm, thus it should know how to include certain aspects to keep customers satisfied, as a form of reassurances such as an exhaustive return policy for all goods (Batarfi et al. 2017). The degree of satisfaction that customers have will be translated with the same amount in REL performance of a firm (Sangwan 2017).

Therefore, hypothesis 9 generated is:

"» H9: Customer services/satisfaction are positively correlated with REL performance.

Quality management. One of the most neglected aspects in good REL systems is the quality of returned products (Sirisawat, Kiatcharoenpol 2018). Quality should not be exchange by quantities, and this can be achieved by potent quality management and quality control systems (Prakash, Barua 2015). The indeterminate quantity of returned products can impact the quality of such products, in case the quality management was weak or non-existing in a firm, and thus eventually impact REL performance (Waqas et al. 2018). Measuring the performance of REL alone, without measuring that of quality management, is completely useless (Ardila Gamboa, Ballesteros Riveros 2018). A product is judged of a good or bad quality 
depending on three quality standards: decent, reasonable and corrupt (Pandian, Abdul-Kader 2017). Operative sustainable REL competence is related to advanced operational performance in terms of better manufacturing quality, lead time, and volume production (Morgan et al. 2018). Good quality management must not overlook the importance of having high-quality customer service (Huang et al. 2015). Decreasing the number of defective products should be a primary objective in a firm's supply chain and quality management in order to reach enhanced REL aspects (Euchi et al. 2019). Improving the quality of goods through the availability of effective quality control and assessment systems increases customer loyalty and thereby increases customer satisfaction (Vlachos 2016). Creating value for consumers is done through maintaining the quality of goods, which is done through good quality management systems that are able to track consumers' feedback and claims (Mahindroo et al. 2018).

Therefore, hypothesis 10 generated is:

"» H10: Quality management is positively correlated with REL performance.

After investigation of various studies in REL area following factors that might be affecting REL performance were identified: management, employees, IT and technology, third-party REL' providers, inventory management, return policy and procedures/guarantee, infrastructure, organizational structure and culture, customer services/ satisfaction, and quality management. These suggested factors will be taken into further analysis and investigation to test if they have a significant and direct effect on REL performance. In order to do so, the first measuring of REL performance methods should be identified, and the next section will discuss this measurement.

\subsection{Measuring REL performance}

Measuring REL performance poses a lot of challenges to firms operating in $\mathrm{B} 2 \mathrm{C}$ e-commerce field. In order to facilitate REL measurement process, the authors discussed several criteria that should be taken into consideration when trying to measure and assess the performance of REL inside the firms. The authors suggested that the most important variables that should be taken into consideration are three main ones: the environmental, social, and economic performances. These variables were the most cited ones, thus they will be taken into consideration when measuring REL performance. Therefore, analysis of the environmental, social, and economic performances, will be further analysed and considered in this research.

Environmental performance. There are three main components of the task environment: government agencies, suppliers, and customers, all of which yielded an improved performance of REL when they were improved (Huang et al. 2015). The present economic environment is categorized by progressive unstable and unpredictable needs, diversity in goods, shorter products' life cycles, as well as augmented competition in the market (Euchi et al. 2019). Opposite to the traditional reverse logistics' systems that rely on separating the economic and social aspects from RL' activities, the updated systems include the economic, social, in addition to the environmental aspect to maintain the sustainability of REL performance (Sudarto et al. 2016). The main concern of REL activities should be not only decreasing costs but should be directed to environmental protection and go green concept as well. Therefore, governments' rules and regulations can improve the quality of recycling, and consequently improve REL (Tan, Guo 2019). To decrease electronic wastes, REL performance can be enhanced via the legislation of new laws and following up on existing ones by the local government (Bal, Satoglu 2018). Another optimal solution to reduce the environmental impact is: developing green performance and reproducing industries and recovery centers that are related to recycling issues (Tosarkani, Amin 2018). The lack of environmental laws and subsidies from the government, manifested by a strict return controlling systems, will discourage firms from thinking of the consequences of their operations on the environment (Bouzon et al. 2015). REL implementation can be highly enhanced and impacted in the presence of strict governmental laws, policies, strategies, and taxes imposing on violating firms, and most importantly, to follow up on the implementation of such laws, and not merely their legislation (Chileshe et al. 2018). From another point of view, consumers can have a high influence on firms to lower environmental polluting by boycotting their products. However, in the absence of the environmental awareness of consumers, this cannot be achieved (Sirisawat, Kiatcharoenpol 2018). There is evidence from already existing law in several countries about the significance of imposing environmental laws to prevent the illegal disposal of all materials of hazardous and non-hazardous substances. This pushed firms to seize the opportunity of improving their REL performance in an attempt to reduce costs (Chinda 2017). Fines paid in case of unrespecting the law have proven to be effective for firms to consider REL as a necessity and not only as another option (Da Silveira Guimarães, Salomon 2015). However, legislation, as well as the implementation of the law, cannot be done without political involvement and commitment, and this is something that is not always there, especially in developing countries (Waqas et al. 2018). The presence of welldetailed, well-explained, and clear environmental laws that oblige firms to reduce pollution and recycle and impose fines for those companies that don't abide, is mandatory (Prakash, Barua 2015). Compliance with such laws also obliges firms to enhance their REL activities in order to reduce costs (Euchi et al. 2019). However, sometimes the presence of conflicting laws is translated in a negative way to REL performance since firms might perceive that governments do not want them to generate profits (Govindan, Bouzon 2018). However, firms wishing to overcome such obstacles should seize the correct implementation of REL, since it will improve the environmental performance of a supply chain by decreasing waste of resources and energy (Keshavarz Ghorabaee et al. 2017). 
Social performance. Social commerce and networks can add value to $\mathrm{B} 2 \mathrm{C}$ e-commerce firms since they contribute in having a better CSR. This is achieved by protecting the environment through activities such as taking the end of use products to recycling processes instead of arbitrarily disposing of them, and the use of social networks to promote the eco-friendly approach (Han, Trimi 2018). REL performance is highly dependent on social performance, which is relatively measured by customers' safety and complaints (Agrawal et al. 2016). In order to improve the social aspect of REL performance, firms must develop policies to track the life cycle of the products by using systems such as the system-dynamics model (Sudarto et al. 2017). It is necessary to satisfy the needs of the B2C e-consumers in REL, but not without taking the environmental and social facets into consideration (Euchi et al. 2019). RLSR, is a new kind of REL that is performed as deliberate, cohesive social responsibility procedures. The most important fact about RLSR is that it is a kind of REL that has a direct effect on the social responsibility model (Sudarto et al. 2016). Few firms take into consideration the importance of considering REL performance in terms of social, environmental, and economic facets. Social sustainability has proven to be very effective in terms of improving REL performance for B2C e-commerce firms (Agrawal et al. 2016). Social factors that impact REL performance can be referred to as those factors that enhance the image of the firm and community as a whole, and they are manifested by aspects such as: respecting human rights and employment rights, respecting work with different suppliers, and respecting the environment as well (Chileshe et al. 2018). The absence of corporate ethical and social responsibilities will not benefit REL performance at all (Waqas et al. 2018). Therefore, taking care of social aspects is very important in diverse supply chain activities, especially towards a good REL' implementation (Chinda 2017).

Economic performance. REL performance is highly dependent on economic performance, which can be measured by ROI, as well as creating and adding value to firms' resources and customers (Agrawal et al. 2016). The finance and economic factors result in huge expenses in REL activities (Waqas et al. 2018). REL has a lot of costs, such as costs of distribution, transportation, recycling, wrapping of hazardous products, testing, restoration, and technology costs, all of which should be handled in an efficient manner since they will impact REL performance (Sirisawat, Kiatcharoenpol 2018). Organizations facing huge causes due to returned products can decrease such costs by applying a strategical and effective REL implementation, which will also increase the performance of the company on different levels (Mahindroo et al. 2018). Returned products' costs alone can range from two to three times a normal cost of a shipment of products. Unfortunately, several firms see REL as something that will happen no matter what, and they do not think that REL can significantly decrease unnecessary costs (Huang et al. 2015). Fortunately, solutions such as introducing reproduction designs, recycling, and disposal, will result in better REL performance and thus lower costs (Govindan, Bouzon 2018). Decreasing expenses of the final disassembly alone can create a lot of benefits, besides effective REL activities, such as: protecting the environment and fortifying position in the market against main competitors (Bouzon et al. 2015). Several companies end up in significant expenses when neglecting to take REL as an important constituent of the firm's supply chain. For them, it is a luxury rather than a necessity (Chileshe et al. 2018). The fruitful REL execution requests economic funding from firms, partners, and even the government, with an ensured and sustained synchronization among all parties involved in REL practices (Prakash, Barua 2015). Minimization of costs can be done through the reuse of recycled goods, which enhances REL performance as well (Chinda 2017). REL activities require a good source of finance for better performance, but at the same time, improved REL performance will increase profit as well (Vlachos 2016).

Therefore, hypothesis 11 generated is H11:

"» REL performance is positively correlated with the company's performance.

Therefore, and to sum things up, in this research assessment of REL performance and its measurement, the following three factors will be further studied: environmental, economic, and social performance. These performance standards were taken into consideration due to their significant importance in REL performance measurement, as suggested by REL scholars and researchers.

\subsection{Measuring companies' performance}

Scholars have discussed how to measure a company's performance by using diverse criteria such as: measuring profits, sales, market share, ROI, resources utilization, and others. Despite the fact that several methods and indicators have been discussed, yet not all were proved to be directly related to the good measurement of performance. Therefore, in this research, the only indicators that will be chosen to measure the performance of companies are the most cited variables by scholars and experts in supply chain management and REL field. The researchers in REL industry suggested three main factors that are behind a good performance measurement, which are: profits and costs, resources' commitment, and operational capacity.

Profits and costs. The main cause to enhance REL activities is to increase profits. This can be achieved by increasing companies' efficiencies (Li et al. 2018). The growth in assets' values during a period is translated into growth in profits (Jianu et al. 2017). Profit maximization should be incorporated in the culture of the organization, even in considering empowering employees. This is due to the fact that centralized decision costs are always higher than those decentralized ones (Batarfi et al. 2017). An important point in decreasing costs and increasing profits is in the firm's volume flexibility. This means that a firm should be able to increase or decrease production depending on demand forecasting procedures in order to sustain the firm's profits (Sri Yogi 2015). 
Resources' commitment. The efficient use of all resources used in supply chain and REL activities will decrease costs because a number of returns will be less, thus it will improve REL performance (Mahindroo et al. 2018). REL performance is highly dependent on environmental performance measured by lower energy usage and ideal usage of inputs (Agrawal et al. 2016). Distributing centers with better efficiency, which is measured by calculating outputs over inputs, have better REL performances, and thus they have better profits and decision-making (Ardila Gamboa, Ballesteros Riveros 2018). To decrease electronic wastes, REL performance should be enhanced via improvement of operations planning and resources sustainability (Bal, Satoglu 2018). The quick progress of online business has increased the number of returned products, and hence increased the number of losses as well. Thus, the sustainability of profits is linked to the commitment to resources and good REL performance (Mahindroo et al. 2018).

Operational capacity. The operations performance is significantly impacted by the integration of REL' systems (Soltany et al. 2018). The operational capacity of a firm can be measured by a company's respective current assets, equipment, and other assets that can be used to increase the efficiency of resources using technology (Jianu et al. 2017). Moreover, the operational capacity, in terms of efficiency, should be considered in every step of REL activities since it is a crucial factor to the success of the firm's supply chain management (Yadav, Barve 2015). At the operational level, a firm must check all procedures taken to prevent and correct defects. This must be done through skilled teams and competent managers (Pandian, Abdul-Kader 2017).

This analysis emphasizes the importance of considering the following three points in measuring a company's performance: profits and costs, resources' commitment, and operational capacity as well. These references will be considered as crucial points to be taken into consideration, as indicated by numerous researches in REL field.

\subsection{Overview of the Middle East region}

The Middle East has a gross population of 350 million people; among them $50 \%$ are less than 25 years old. The young population uses more and more the internet, social media platforms, and digital tools. E-commerce in the Middle East increased by $29 \%$ from the period between 2011 and 2017, where it registered \$7 billion in 2011 and $\$ 15$ billion in 2015. This increase can be explained by the enormous jump in the Middle East's e-commerce users, in addition to the increase in the number of local retailers working online and offering customers products and services that were not available before (Sanyala, Hisamb 2019). SMEs are the main providers of employment in the Middle East region, whereby they represent around 80 to $90 \%$ of the private business sector (Mouselli, Khalifa 2017). This indicates a huge opportunity for e-logistics improvement (Mouchawar 2017). However, challenges still exist in the Middle East. Actually, the logistical system in the Middle East is still under development. For instance, several Middle Eastern countries suffer from bad infrastructure, absence of postal codes, IT, and software development systems (Mouchawar 2017). Nevertheless, most countries in the Middle East still lack specific instruments to institute internet-focused e-commerce networks. Ecommerce companies operating in this area acquired little knowledge of the business' logistics (Zaidan 2017). Adding to these challenges, there exists a state of shortage in finding skilled and qualified managers, a lack in financing since the presence of investors funding firms operating in e-commerce industry is relatively low, and logistical problems manifested by problems in last-mile delivery, warehousing, mitigate losses, and payments (Sanyala, Hisamb 2019). Two countries, Lebanon and Syria, were selected for deeper analysis because of specifics.

Lebanon's peculiarities, opportunities, and challenges. Lebanon is situated at the middle of the Eastern Mediterranean area, and this gives it a strategic commercial connection between the Middle East and Europe. It is considered as a developing country with a middle-income population and recently increased the poverty rate. Nonetheless, Lebanon has a high degree of urbanization. Beirut alone has more than 400,000 Lebanese residents, out of a total of 6 million Lebanese population (Bahn, Abebe 2017). Lebanon is considered as a crucial member and commercial partner for the European Union after signing the Euro-Mediterranean agreement in partnership. Therefore, Lebanon offers a stimulating point to gain a better understanding of e-commerce in the Middle East region (Abebe et al. 2020). Lebanon has several bilateral and regional trade agreements with the European Union, including the Euro-Mediterranean partnership. Lebanon can be taken as a good example for other developing countries in the Middle East since Lebanon is considered to have leadership in terms ICT development. Moreover, Lebanon's location gives it a potent commercial liaison between the Mediterranean, East Asia, and India. The Lebanese economic system is considered a free competitive market and a "laissez-faire", which is highly preferred by several e-commerce businesses. Lebanon registered first place in terms of using social media in the Middle East, hence giving it an opportunity that awaits seizing profitably using ecommerce (El Rassi 2020). In spite of the presence of such opportunities, challenges still exist in Lebanon to perform e-commerce such as low-quality internet and communication services, high prices of internet and phone calls, absence of governmental e-services, and lack of governmental interference in terms of legal matters, inefficient delivery, and insecure payments' systems. Due to such problems, several firms are not considering this region to conduct their e-business (El Rassi 2020). Lebanon is behind in terms of using advanced technology and in terms of innovation due to the fact that investments in R\&D are relatively low (Skafi et al. 2020). Nevertheless, Lebanon faces challenges in terms of bad infrastructure, collapsing economy, and political corruption. 
Syria's peculiarities, opportunities, and challenges. Syria is geographically located in the Levant area in the Mediterranean region; it borders Lebanon from its south, a location that granted it strong connections with several neighbouring countries and other countries such as Russia, China, and central Asia, thereby connecting these areas to broader streams of international trade (Anderson 2018). Syria, a developing country, has a low-middle class income with a population of approximately 19 million. Syria's economic liberalization started in 1990 after realizing the appearance of business networks that are completely dependent on the regime's readiness to award them monopolization of the market (Ibeh, Kasem 2011). Syria was open to the international economy and cultural inspirations till 2011, when the civil war happened. During this time, many businesspersons were interested in conducting business there. The common point was that several Syrian managers were educated in international universities, which explains the reason behind resemblances in behaviour between Western and Syrian executives (Alamir et al. 2019).

Despite such opportunities, Syria faces several challenges that starts with the shortage of financial resources, which clearly appears in the high costs of doing ebusiness, and struggle in gathering relevant information (Mouselli, Khalifa 2017). Moreover, the Syrian ICT sector is still in its beginning, even compared to other countries in the Middle East, Syria has one of the worst ICT sector (Ibeh, Kasem 2011). ICT in Syria suffers a lot due to the currently weak infrastructure, bad internet connection, and complete absence of e-security. Moreover, employee challenges also exist due to the presence of a state of illiteracy in ICT. The problem is that improving ICT is getting more and more difficult due to the state of brain drain that happened in the country because skilled employees left the country either due to higher salaries and better quality of life in other countries or because of the current civil war happening there (Alsaeed, Adams 2015). Actually, this civil war not only leads to financial and economic instabilities but also impacted diverse economic, social, and entrepreneurial facets. Moreover, in 2016 Syria's GDP decreased by $63 \%$ due to this war, resulting in more than 9 million unemployed and the leaving of a high number of firms operating there (Alamir et al. 2019). The Syrian regime imposed obstacles even before the occurrence of the civil war by creating political challenges manifested by political barriers such as the absence of freedom of the press, and the strict access to the Internet, which is only permissible through the government. The Syrian government failed to remove trade barriers associated with the European Common Agricultural Policy (Anderson 2018). Concerning the socio-economic challenges, they occurred in Syria as a result of corruption and poverty (Alsaeed, Adams 2015). Nonetheless, Syria's government has high levels of bureaucracy and taxes that must be decreased, in addition to enhancing the country's infrastructure.
Taking into consideration specific of both countries, the assumption that these factors are similar to other developing countries were made, so these two countries were chosen for research of REL performance.

\section{Research methodology for identifying REL' systems}

The analysis of the review of literature emphasized the probable significance of the main ten factors that might be affecting REL performance. These factors are management, quality management, organizational structure and culture, IT and technology, customer services/satisfaction, return policy and procedures/guarantee, employees, infrastructure, inventory management, and third-party REL providers. This, resulted in the following two research objectives: the first one is to identify the most important factors that affect REL performance, and the second one is to see if REL, in turn, affects the companies' performance. This led to two research questions, RQ1: what are the most important factors that are directly correlated with REL performance, and to what level do these factors impact it?; and RQ2: Is enhanced REL performance positively correlated with the companies performance, and to what extent? Therefore, seeking to reach the study's objectives and to find answers for its formulated research questions, a proposed theoretical framework is initiated in Figure 2. Thus, this led to the formulation of the below eleven hypotheses:

"» $\mathrm{H} 1$ : Management is positively correlated with REL performance;

"»» H2: Incompetent employees are negatively correlated with REL performance;

"» H3: IT is positively correlated with REL performance;

"» $\mathrm{H} 4$ : Absence of effective third-party REL providers is negatively correlated with REL performance;

"» H5: Bad inventory management is negatively correlated with REL performance;

"»» H6: Absence of return policy and procedures/guarantee are negatively correlated with REL performance;

"» H7: Infrastructure is positively correlated with REL performance;

"» H8: Organizational structures and cultures are positively correlated with REL performance;

"» H9: Customer services/satisfaction are positively correlated with REL performance;

"» H10: Quality management is positively correlated with REL performance;

"»» H11: REL performance is positively correlated with company's performance.

The next step is to validate the above hypotheses by using questionnaires and SEM through IBM SPSS Amos software (https://www.ibm.com/products/structural-equation-modeling-sem). 


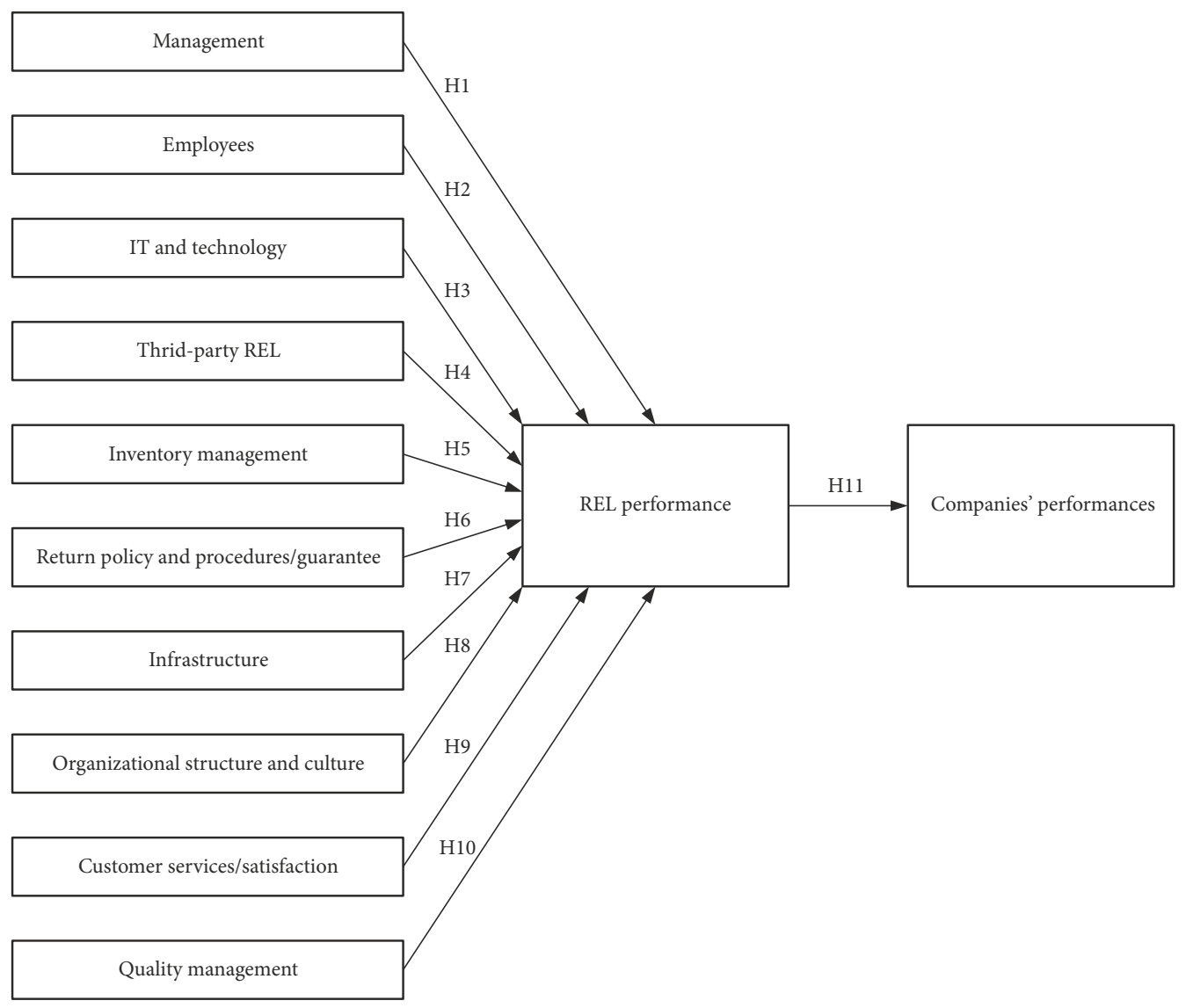

Figure 2. Theoretical framework (source: compiled by authors 2020)

A five-point Likert scale questionnaire was sent to 652 e-commerce companies in Lebanon and Syria using Google forms questionnaires. The respondents' selection criteria were as follows:

"» working in supply chain management for at least 2 years;

"» familiar with e-logistics and REL;

"» have a minimum of Bachelor's degree in business administration;

"'» been in the same company for at least 2 years.

The questionnaire is made up of a total of 61 questions, out of which 7 questions are demographics and 54 questions ask about REL' factors and the company's performance. The questions were taken from articles by authors who are experts in the field of REL. The 61 asked questions with their relative source are summarized in Table 5.

A total of 509 were returned. Since REL is the most important task in our study, all responses from companies that were not involved in REL activities were eliminated. Thus, the total final results were 412 answers $(63.19 \%$ response). A five-point Likert scale was used (1 - strongly disagree, 2 - disagree, 3 - neutral, 4 - agree, 5 - strongly agree) to perform the analysis.

In order to check the validity of the questionnaire used, Cronbach's alpha value was applied. For a questionnaire to be valid, the value of Cronbach's should be between 0.70 and 1.00. All of the below values are greater than the alpha value of 0.70 , which indicates reliability. Thus, this proves that results for the diverse latent variables under study are reliable. The summary of alpha values is documented in Table 6.

Concerning sampling validity, two famous tests were applied in measuring its adequacy. The first one is the KMO test, which indicates significance when its value is higher than 0.5 . In this study $\mathrm{KMO}=0.739$, which indicates reliability. The second test is Bartlett's test value, it indicates significance when its value is less than 0.500 . In this study Bartlett's test $=0.000$, which indicates reliability. Thus, this analysis proves that the compulsory adequacy level is satisfied. Moreover, the AVE test was applied for further test the validity. In case the value of AVE is more than or equals to 0.5 , then this indicates the presence of validity. Results of AVE are represented in Table 7.

For constructing the research model and test the formulated hypotheses, IBM SPSS Amos software was utilized. The constructed model is found in Figure 3. Using IBM SPSS Amos software, the model fit presence will be examined. IBM SPSS Amos software use as indicator the standardized estimates (coefficients) to see the correlations between the variables under study. This is a suitable indicator for correlation analysis since Pearson correlation cannot be applied since a Likert scale was applied in the sent questionnaire. Table 8 explains the important indicators that explain the existence of a model fit in this study. 
Table 5. Questions of the questionnaire sent (source: compiled by authors 2020)

\begin{tabular}{|c|c|}
\hline \multicolumn{2}{|l|}{$\begin{array}{l}\text { Respondent's demographics: } \\
\text { "» age; } \\
\text { "» gender; } \\
\text { "» education; } \\
\text { "» job position; } \\
\text { "» years of experience in the supply chain; } \\
\text { "» years within the same company; } \\
\text { "» country of operation. }\end{array}$} \\
\hline Questions & Source \\
\hline \multicolumn{2}{|l|}{ Factors affecting REL's performance } \\
\hline \multicolumn{2}{|l|}{ Management } \\
\hline MGT1: Managers continuously perform strategic planning for diverse REL activities. & Waqas et al. (2018) \\
\hline MGT2: Managers are committed to achieving the firm's objectives, including REL ones. & Sirisawat, Kiatcharoenpol (2018) \\
\hline $\begin{array}{l}\text { MGT3: Managers lack cooperation with REL professionals, partners, and third-party REL } \\
\text { providers. }\end{array}$ & Prakash, Barua (2015) \\
\hline MGT4: Managers are well-experienced and aware of and understand diverse REL practices. & Waqas et al. (2018) \\
\hline \multicolumn{2}{|l|}{ Organizational structure and culture } \\
\hline $\begin{array}{l}\text { OSC1: REL programs' evaluation, procedures, and guidelines, are well-explained, understood, } \\
\text { and written. }\end{array}$ & Euchi et al. (2019) \\
\hline OSC2: REL is not integrated with supply chain business processes. & Euchi et al. (2019) \\
\hline OSC3: There is a lack of flexibility to change from traditional REL systems to new ones. & Euchi et al. (2019) \\
\hline OSC4: No efficient and effective REL systems are used to monitor returns, and recalls are used. & Euchi et al. (2019) \\
\hline \multicolumn{2}{|l|}{ Return policy and procedures/guarantee } \\
\hline GRP1: Return procedures are consistent and relatively easy. & Euchi et al. (2019) \\
\hline $\begin{array}{l}\text { GRP2: The return policy includes product returns by the customers in cases such as product end- } \\
\text { of-life and defects. }\end{array}$ & Euchi et al. (2019) \\
\hline $\begin{array}{l}\text { GRP3: In case of defective/wrong product, the firm claims no liability whatsoever in this matter } \\
\text { to refund or repair. }\end{array}$ & Euchi et al. (2019) \\
\hline \multicolumn{2}{|l|}{ Employees } \\
\hline $\begin{array}{l}\text { EMP1: The Feel-good factors such as employee's morale, individual satisfaction are obtained in } \\
\text { the company. }\end{array}$ & Govindan, Bouzon (2018) \\
\hline EMP2: Number of employees is positively related to REL implementation & Mahindroo et al. (2018) \\
\hline $\begin{array}{l}\text { EMP3: Only skilled, experienced, and well-educated employees that are capable of handling } \\
\text { returns and other REL activities are hired. }\end{array}$ & Mahindroo et al. (2018) \\
\hline \multicolumn{2}{|l|}{$\begin{array}{l}\text { Inventory management } \\
\end{array}$} \\
\hline IMGT1: The firm can forecast the approximate demand of goods/products & Sirisawat, Kiatcharoenpol (2018) \\
\hline IMGT2: Risk of storage of hazardous materials is appropriately managed & Prakash, Barua (2015) \\
\hline IMGT3: Reasons for returns are reasonable and are not the company's fault. & Sirisawat, Kiatcharoenpol (2018) \\
\hline \multicolumn{2}{|l|}{ IT and technology } \\
\hline IT1: The firm has the most updated technological systems and info for REL processes. & Han, Trimi (2018) \\
\hline IT2: Direct computer-to-computer links with key vendors are installed. & Sirisawat, Kiatcharoenpol (2018) \\
\hline $\begin{array}{l}\text { IT3: Your Website/social media users is extremely easy in terms of using, ordering online, and } \\
\text { returning a product }\end{array}$ & Euchi et al. (2019) \\
\hline \multicolumn{2}{|l|}{ Infrastructure } \\
\hline INF1: No technological infrastructure to adopt REL practices is available. & Waqas et al. (2018) \\
\hline INF2: Your firm has a strong infrastructure facility (storage, transportation). & Sirisawat, Kiatcharoenpol (2018) \\
\hline INF3: Your country suffers from bad infrastructure( electricity, bad road conditions, etc.) & Waqas et al. (2018) \\
\hline INF4: Your company has a robust disaster-resilient infrastructure and transport facilities & Waqas et al. (2018) \\
\hline INF5: Your company has a strong system to monitor returns. & $\begin{array}{l}\text { Sirisawat, Kiatcharoenpol (2018); } \\
\text { Prakash, Barua (2015) }\end{array}$ \\
\hline \multicolumn{2}{|l|}{ Third-party REL } \\
\hline TPP1: Well-trained supply chain partners assist in REL implementation and management. & Govindan, Bouzon (2018) \\
\hline $\begin{array}{l}\text { TPP2: Cooperation with business partners in the supply chain is high in the REL } \\
\text { implementation. }\end{array}$ & Sirisawat, Kiatcharoenpol (2018) \\
\hline
\end{tabular}


End of Table 5

\begin{tabular}{|c|c|}
\hline Questions & Source \\
\hline $\begin{array}{l}\text { TPP3: Third-party contribute in risk-sharing, culture compatibility, information system } \\
\text { technology, supplier mentoring, employment stability, and knowledge management. }\end{array}$ & Prakash, Barua (2015) \\
\hline \multicolumn{2}{|l|}{ Customer services/satisfaction } \\
\hline CS1: The buyer-seller relationship is good. & Euchi et al. (2019) \\
\hline $\begin{array}{l}\text { CS2: You are ready to dedicate your staff and resources to REL activities we are conducting with } \\
\text { this client. }\end{array}$ & Euchi et al. (2019) \\
\hline CS3: Your company dedicates its staff to clients' customer service $24 / 7$. & Euchi et al. (2019) \\
\hline \multicolumn{2}{|l|}{ Quality management } \\
\hline QM1: Your firm performs a continuous inspection for quality problems (quality at source). & Morgan et al. (2018) \\
\hline $\begin{array}{l}\text { QM2: In the case of returning a defected product, your firm identifies the quality problems and } \\
\text { make sure it will not happen again. }\end{array}$ & Morgan et al. (2018) \\
\hline QM3: In your firm, "quality” includes reducing the environmental impact of our RL practices & Morgan et al. (2018) \\
\hline \multicolumn{2}{|l|}{ REL performance } \\
\hline \multicolumn{2}{|l|}{ Economic performance } \\
\hline ECO1: REL activities resulted in increased revenues & Agrawal et al. (2016) \\
\hline ECO2: Initial and operating costs for REL activities are high. & Chileshe et al. (2018) \\
\hline $\begin{array}{l}\text { ECO3: REL resulted in cost savings by increasing revenue from the sale of recyclables, } \\
\text { recapturing value, and green policy returns. }\end{array}$ & Chileshe et al. (2018) \\
\hline \multicolumn{2}{|l|}{ Environmental performance } \\
\hline ENV1: The firm applies the concept of minimum energy consumption and pollution. & Chileshe et al. (2018) \\
\hline ENV2: Enhancing the green image of the company is among the firm's strategic objectives & $\begin{array}{l}\text { Da Silveira Guimarães, Salomon } \\
\text { (2015) }\end{array}$ \\
\hline ENV3: The firm complies with environmental regulations and standards. & Shaik, Abdul-Kader (2018) \\
\hline \multicolumn{2}{|l|}{ Social performance } \\
\hline SOC1: Among the firm's REL objectives is creating a number of social and educational projects. & Shaik, Abdul-Kader (2018) \\
\hline SOC2: The firm meets the community expectations in terms of generating a large number of jobs. & $\begin{array}{l}\text { Da Silveira Guimarães, Salomon } \\
(2015)\end{array}$ \\
\hline $\begin{array}{l}\text { SOC3: Your country lacks law enforcement and legislation concerning REL practices such as } \\
\text { recycling or returning a product. }\end{array}$ & Shaik, Abdul-Kader (2018) \\
\hline \multicolumn{2}{|l|}{ Companies' performance } \\
\hline \multicolumn{2}{|l|}{ Operational capacity } \\
\hline OPC1: Firms' can handle a customer's return requirements quickly. & Euchi et al. (2019) \\
\hline OPC2: The collection centers are always ready and available. & Yadav, Barve (2015) \\
\hline OPC3: Firm's capacity can handle a huge number of returned products and process them directly. & Euchi et al. (2019) \\
\hline \multicolumn{2}{|l|}{ Costs incurred } \\
\hline CP1: Profit can be generated by reusing or recovering material. & Pandian, Abdul-Kader (2017) \\
\hline CP2: costs of shipments, transportation, and delivery are relatively high. & Morgan et al. (2018) \\
\hline CP3: Initial capital for investment in REL operations is available. & Li et al. (2018) \\
\hline \multicolumn{2}{|l|}{ Commitment to resources' efficiency } \\
\hline $\begin{array}{l}\text { CR1: The firms decrease the use of raw materials by replacing them with recovered ones as well as } \\
\text { the reduction of final disposal costs. }\end{array}$ & Mahindroo et al. (2018) \\
\hline $\begin{array}{l}\text { CR2: The firm meets cost, quality, and environmental impacts while conserving its valuable } \\
\text { resources. }\end{array}$ & Li et al. (2018) \\
\hline $\begin{array}{l}\text { CR3: The firm collects raw resources from wholesalers and consumers in order to maintain the } \\
\text { efficiency of its resources. }\end{array}$ & Sri Yogi 2015; \\
\hline $\begin{array}{l}\text { CR4: The degree of financial, human, and technological resources is done effectively and } \\
\text { efficiently. }\end{array}$ & Mahindroo et al. (2018) \\
\hline CR5: The collection of raw resources from wholesalers is continuous and updated. & Euchi et al. (2019) \\
\hline
\end{tabular}


Table 6. Values of Cronbach's alpha (source: compiled by authors 2020)

\begin{tabular}{|l|c|}
\hline \multicolumn{1}{|c|}{ Factor } & Cronbach's alpha \\
\hline Management & 0.979 \\
\hline Employees & 0.706 \\
\hline IT and technology & 0.973 \\
\hline Third-party REL & 0.719 \\
\hline Inventory management & 0.793 \\
\hline Return policy and procedures/guarantee & 0.777 \\
\hline Infrastructure & 0.869 \\
\hline Organizational structure and culture & 0.983 \\
\hline Customer services/satisfaction & 0.956 \\
\hline Quality management & 0.767 \\
\hline
\end{tabular}

Table 7. Values of AVE

(source: compiled by authors 2020)

\begin{tabular}{|l|l|}
\hline \multicolumn{1}{|c|}{ Factor } & AVE \\
\hline Management & 0.865 \\
\hline Employees & 0.580 \\
\hline IT and technology & 0.843 \\
\hline Third-party REL & 0.525 \\
\hline Inventory management & 0.651 \\
\hline Return policy and procedures/guarantee & 0.560 \\
\hline Infrastructure & 0.795 \\
\hline Organizational structure and culture & 0.870 \\
\hline Customer services/satisfaction & 0.860 \\
\hline Quality management & 0.553 \\
\hline
\end{tabular}

Table 8. Model fit data (source: compiled by authors 2020)

\begin{tabular}{|c|c|c|c|c|c|c|c|c|c|}
\hline Model & CMIN & DF & CMIN/DF & $p$ & CFI & GFI & RMSEA & SRMR & $p$-close \\
\hline Default model & 0.114 & 526 & 2.158 & 0.000 & 0.956 & 0.875 & 0.053 & 0.038 & 0.114 \\
\hline
\end{tabular}

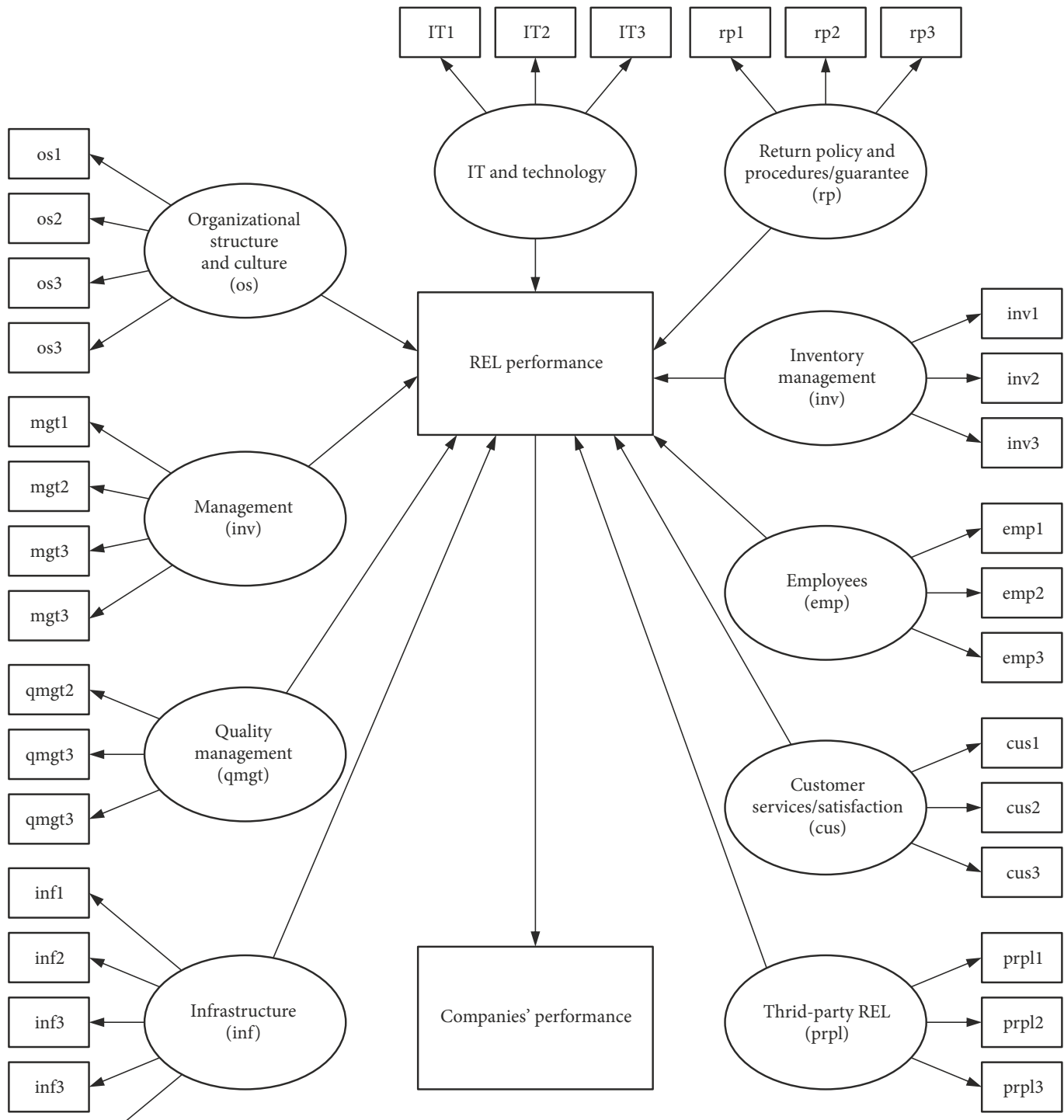


CMIN: it is the model's chi-square, it must be divided by the DF to test the model fit. The CMIN/DF must be between 1 and 3. In this model CMIN/DF $=2.158$, which proves the existence of a model fit.

CFI: it serves in comparing the model fit with respect to the independent variables. CFI explains the difference between the observed and expected covariance matrices. CFI must be equal to or more than 0.950 for the existence of a model fit. In this model CFI $=0.956$, which proves the existence of a model fit.

GFI: it measures the fit between the hypothesized model and the observed covariance matrix. GFI must be equal to or more than 0.90 to indicate the existence of model fit, in our study GFI $=0.875$, which indicates a good model fit since it is still in the acceptable range variance.

RMSEA: it is used as a tool for regulating the sample size where chi-square statistics are applied. It is employed as an addition to the tests of chi-square fit. RMSEA should be equal to or less than 0.060 , which is the case since RM$\mathrm{SEA}=0.054$. It proves the existence of a model fit.

SRMR: it has two roles. First, it tells if any value is missing from the data, and second it tells the discrepancy's square root among the sample covariance and the model matrices. SRMR should be equal to or less than 0.08. In this study SRMR $=0.038$, which indicates a model fitness.

$p$-close: it is the $p$-value for investigating the null hypothesis, it states that the sample of RMSEA should not be larger than 0.05. $p$-close gives an evaluation concerning the close fit test, whereas the $p$-value gives an evaluation concerning the exact fit test. $p$-close must be more than 0.05 to prove a good measure fit index. This is the case in this study since $p$-close $=0.114$.

Therefore, this analysis proves that the proposed model is fit and can be applied to test the formulated hypotheses, and it proves that the results recorded are valid. Hence, the managerial implication for firms wishing to improve their REL performance will be considered effective, due to the presence of this model fit, reliability, and validity.

\section{Discussion of the results}

Having proved the existence of the model fit, the values of the correlation coefficient should be given and analysed. This will be divided into two parts. The first one is related to factors impacting REL performance, whereas the second will be directed for REL activities impacting the performance of the company. The Correlation coefficient of factors impacting REL performance and the correlation coefficient of REL on companies' performances are summarized in Table 9.

To proceed with the analysis, studying the correlation between the variables with REL performance is a must. A value of correlation coefficient between 0 and 0.3 is considered a weak positive correlation, between 0.3 and 0.6 is a moderate positive correlation, whereas between 0.6 and 1.0 proves a strong positive correlation. Consequently, if the value is between 0 and -0.3 , is considered a weak negative correlation, between -0.3 and -0.6 is a moderately weak correlation, whereas between -0.6 and -1.0 proves a strong negative correlation. Therefore, management (0.187), organizational structure and culture (0.268), IT and technology (0.253), and quality management (0.04) have a weak positive correlation with REL performance. Moreover, customer services/satisfaction (0.574), and infrastructure (0.444), has a moderate positive correlation with REL performance. On the other hand, the factors: the absence of return policy and procedures/guarantee $(-0.028)$, bad inventory management $(-0.012)$, incompetent employees $(-0.05)$, and absence of third-party REL' providers $(-0.034)$, all recorded a weak negative correlation with REL performance. This means that these factors will result in bad REL performance in case of their absences. As for the effect of REL performance (0.144), it has a weak positive correlation with companies' performance. This means that improvement in REL will result in improved companies' performance. A conclusion can be made from this analysis to see if the formulated hypotheses are rejected or not rejected.

Table 9. Correlation coefficient of factors affecting REL (source: compiled by authors 2020)

\begin{tabular}{|c|c|c|}
\hline Factors under study & Correlation coefficient & $p$-value \\
\hline Management $\rightarrow$ REL performance & 0.187 & ** \\
\hline Incompetent employees $\rightarrow$ REL performance & -0.05 & ** \\
\hline IT and technology $\rightarrow$ REL performance & 0.253 & ** \\
\hline Absence of third-party REL' providers $\rightarrow$ REL performance & -0.034 & 0.297 \\
\hline Bad inventory management $\rightarrow$ REL performance & -0.012 & 0.658 \\
\hline Absence of return policy and procedures/guarantee $\rightarrow$ REL performance & -0.028 & $* *$ \\
\hline Infrastructure $\rightarrow$ REL performance & 0.444 & ** \\
\hline Organizational structure and culture $\rightarrow$ REL performance & 0.268 & ** \\
\hline Customer services/satisfaction $\rightarrow$ REL performance & 0.574 & $* *$ \\
\hline Quality management $\rightarrow$ REL performance & 0.04 & $* *$ \\
\hline REL performance $\rightarrow$ Companies' performance & 0.144 & $0.047^{\star}$ \\
\hline
\end{tabular}

Notes: ${ }^{\star *} p$-value $<0.1,{ }^{\star} p$-value $<0.05$. 
The hypotheses test of significance is based on $p$-value $<0.05$ level of significance. Although some hypotheses show negative correlation, the analysis showed that any $p$-value $>0.05$ is respectively rejected. Therefore, the null hypothesis is always insignificant of correlation therefore:

"» H0: correlation is = 0 (null);

"» Ha: correlation is $\neq 0$ (alternative).

Thus a $p$-value $<0.05$ level of significance shows that $\mathrm{H} 0$ is not rejected. This means that there is a 0 correlation in the population for this tested variable from which the sample was selected. Whereas a $p$-value $>0.05$ means that $\mathrm{Ha}$ is the one that is not rejected. However, certain sentences were rephrased to eliminate the confusion.

Hypothesis 1 (H1). Management is positively correlated with REL performance (correlation coefficient $=0.187$, $p<0.05$ ), is not rejected, since the $p$-value is less than 0.05 . This indicates that if a firm has good management, then REL performance will be improved. Thus, when management goes up by 1 SD, REL performance goes up by 0.187 SDs.

Hypothesis 2 (H2). Incompetent employees are negatively correlated with REL performance (correlation coefficient $=-0.05, p<0.05$ ), is not rejected since the $p$-value is less than 0.05 . This indicates that unskilled employees in REL practices will have a negative impact on REL performance. Thus, when incompetent employees go up by 1 $\mathrm{SD}, \mathrm{REL}$ performance goes down by $0.05 \mathrm{SD}$.

Hypothesis 3 (H3). IT is positively correlated with REL performance (correlation coefficient $=0.253, p<0.05$ ), is not rejected, since the $p$-value is less than 0.05 . This indicates that if a firm has good IT, then REL performance will be improved. Thus, when IT goes up by 1 SD, REL performance goes up by 0.253 SDs.

Hypothesis 4 (H4). The absence of effective third-party REL providers is negatively correlated with REL performance (correlation coefficient $=-0.034, p=0.297$ ), is rejected due to a $p$-value higher than 0.05 .

Hypothesis 5 (H5). Bad inventory management is negatively correlated with REL performance (correlation coefficient $=-0.012 ; p=0.658)$, is rejected, due to a $p$ value $>0.05$.

Hypothesis 6 (H6). Absence of return policy and procedures/guarantee are negatively correlated with REL performance (correlation coefficient $=-0.028, p<0.05$ ), is not rejected since the $p$-value is less than 0.05 . This indicates that if a firm does not have return policies and guarantees, its customers will not be willing to buy from it. This will result in bad REL performance. Therefore, when the return policy and procedures/guarantee go up by $1 \mathrm{SD}$, REL performance goes down by 0.028 SDs.

Hypothesis $7(\mathrm{H} 7)$. Infrastructure is positively correlated with REL performance (correlation coefficient $=0.444$, $p<0.05$ ), is not rejected, since the $p$-value is less than 0.05 . This indicates that if a firm has a potent infrastructure, then the REL performance will be improved. Thus, when infrastructure goes up by $1 \mathrm{SD}$, REL performance goes up by 0.444 SDs.
Hypothesis 8 (H8). Organizational structures and cultures are positively correlated with REL performance (correlation coefficient $=0.268, p<0.05$ ), is not rejected since the $p$-value is less than 0.05 . This indicates that if a firm has good organizational structures and cultures, then REL performance will be improved. Thus, when organizational structure and cultures go up by $1 \mathrm{SD}$, REL performance goes up by 0.268 SDs.

Hypothesis 9 (H9). Customer services/satisfaction are positively correlated with REL performance (correlation coefficient $=0.574, p<0.05$ ), is not rejected since the $p$ value is less than 0.05 . This indicates that if a firm is able to achieve customer satisfaction through good services, then REL performance will be improved. Thus, when customer satisfaction goes up by $1 \mathrm{SD}$, REL performance goes up by 0.574 SDs.

Hypothesis 10 (H10). Quality management is positively correlated with REL performance (correlation coefficient $=0.04, p<0.05$ ), is not rejected, since the $p$-value is less than 0.05 . This indicates that if a firm has good quality management of its products, this will result in better REL performance. Thus, when a firm's quality management goes up by $1 \mathrm{SD}$, REL performance goes up by 0.04 SDs.

Hypothesis 11 (H11). REL performance is positively correlated with the company's performance (correlation coefficient $=0.144, p<0.05$ ), is not rejected since the $p$ value is less than 0.05 . This indicates that if a firm is able to achieve good REL performance, then the companies' performance will be improved. Thus, when REL performance goes up by $1 \mathrm{SD}$, then the companies' performance goes up by 0.144 SDs. All the formulated hypotheses and their respective results are summarized in Table 10.

Therefore, a firm that is willing to improve its REL performance should focus on all the factors that were not rejected in the formulated hypotheses. These factors are: management, quality management, organizational structure and culture, IT and technology, gustomer services/ satisfaction, return policy and procedures/guarantee, employees, and infrastructure. Moreover, once the firm is able to improve its REL performance, it will be able to achieve better performance as well.

A head to head comparison between companies' performing e-logistics in Lebanon and Syria shows a lot of similarities and few differences. Despite the fact that the final Lebanese companies were in total 250 companies, and the Syrian ones were 162, the two countries showed some similarities. These similarities are briefed in three main points. First, the eight factors identified as important in Lebanon: management, quality management, organizational structure and culture, IT and technology, customer services/satisfaction, return policy and procedures/guarantee, employees, and infrastructure, all had approximately the same significance in Syria. Moreover, the other factors mentioned in the study did not have that much significance on REL performance. Second, REL performance was directly related to an improved efficiency in companies' performance in Lebanon and Syria. 
Table 10. Formulated hypothesis with their corresponding results (source: compiled by authors 2020)

\begin{tabular}{|c|c|c|c|}
\hline Hypothesis & $\begin{array}{l}\text { Correlation } \\
\text { coefficient }\end{array}$ & $p$-value & $\begin{array}{l}\text { Rejected / not } \\
\text { rejected }\end{array}$ \\
\hline H1: Management is positively correlated with REL performance. & 0.187 & $* *$ & not rejected \\
\hline H2: Incompetent employees are negatively correlated with REL performance. & -0.05 & $* *$ & not rejected \\
\hline H3: IT and technology is positively correlated with REL performance. & 0.253 & ** & not rejected \\
\hline $\begin{array}{l}\text { H4: The absence of effective third-party REL providers is negatively correlated with REL } \\
\text { performance. }\end{array}$ & -0.034 & 0.297 & rejected \\
\hline H5: Bad inventory management is negatively correlated with REL performance. & -0.012 & 0.658 & rejected \\
\hline $\begin{array}{l}\text { H6: Absence of Return policy and procedures/guarantee are negatively correlated with REL } \\
\text { performance. }\end{array}$ & -0.028 & ** & not rejected \\
\hline H7: Infrastructure is positively correlated with REL performance & 0.444 & ** & not rejected \\
\hline H8: Organizational structures and cultures are positively correlated with REL performance. & 0.268 & ** & not rejected \\
\hline H9: Customer services/satisfaction are positively correlated with REL performance. & 0.574 & ** & not rejected \\
\hline H10: Quality management is positively correlated with REL performance. & 0.04 & ** & not rejected \\
\hline H11: REL performance is positively correlated with the company's performance. & 0.144 & $0.047^{\star}$ & not rejected \\
\hline
\end{tabular}

Notes: ${ }^{* *} p$-value $<0.1,{ }^{*} p$-value $<0.05$.

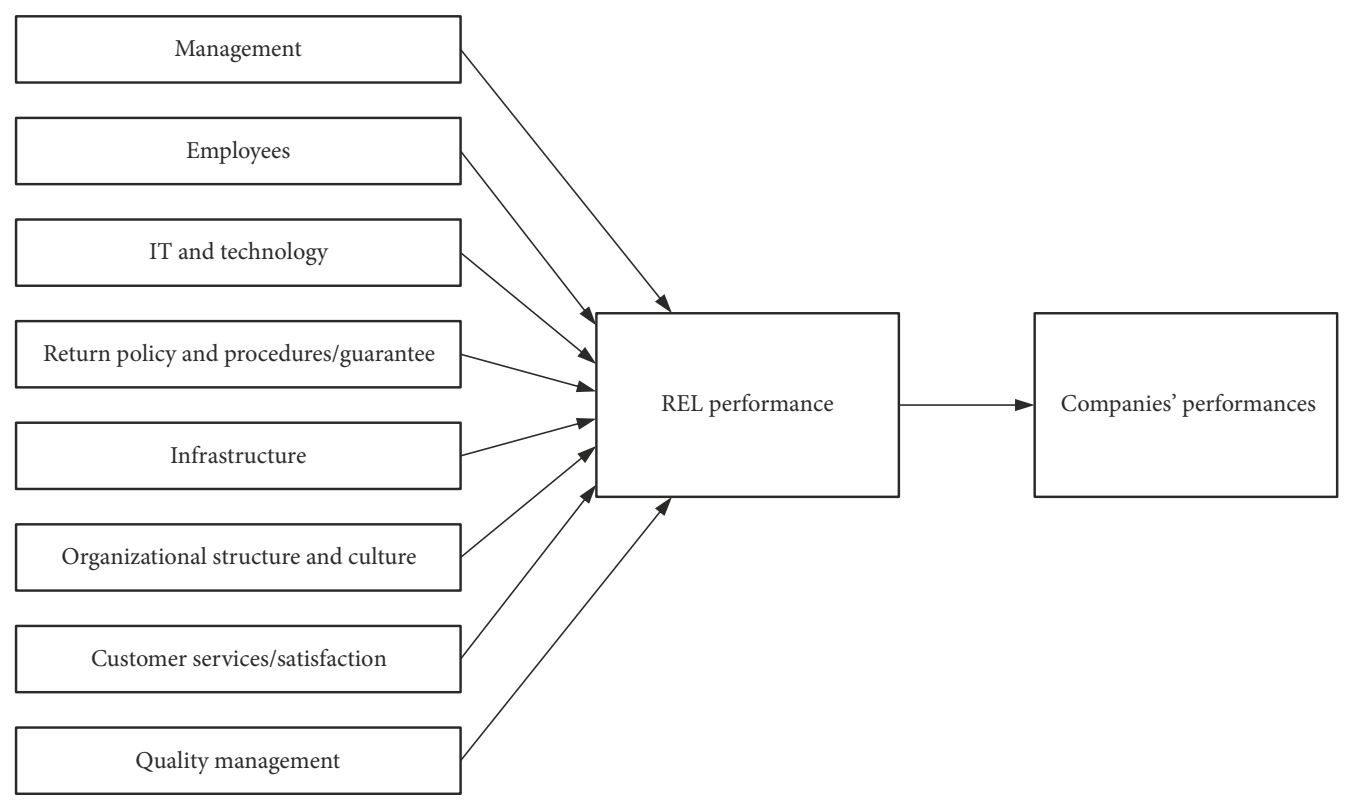

Figure 4. The concluding model for increasing REL performance (source: compiled by authors 2020)

Third, both countries share some patterns in terms of consumer behaviour, such as comparing prices to quality. This may be due to the very similar culture in both countries, which might have led to the same exact answers in a high number of questions.

Concerning the differences in REL in Lebanon and Syria, they can be summarized by two main points. First, concerning the most demanded products online in Lebanon; they were smart mobile phones and sports equipment. Whereas in Syria, the consumers preferred buying laptops and tablets the most. Second, Lebanese consumers preferred high customer service when it comes to having customer satisfaction. However, the Syrian consumers cited as the most important thing in customer satisfaction the good prices.
As conclusion, both Lebanon and Syria have a lot of commonalities that make it easier to be taken into consideration for e-businesses willing to take part in the Middle East. Thus, very similar e-commerce strategies can be successful for both countries, with minor modifications required.

\section{The concluding model for increasing REL performance}

After identifying the presence of ten main factors that might be impacting the performance of REL's systems, eight out of the ten factors were considered to have a significant impact on REL's activities, which were: management, quality management, organizational structure and 
culture, IT and technology, customer services/satisfaction, return policy and procedures/guarantee, employees, and infrastructure. In other words, improving the performance of these eight factors will result in improved REL's performance. These factors are represented in Figure 4.

On another side, from the previous analysis done it was proved that REL's systems, in turn, impact companies' performance. Thus, improving REL's systems will improve the performance of B2C e-commerce companies. Moreover, improvements in REL's systems will result automatically in improved efficiency of companies' performances

\section{Conclusions}

The internet and IT have made a significant impact on business processes. One of the most crucial things that the internet brought is the creation of e-commerce, which proved to have several benefits in terms of saving costs and increasing profits. However, to reap the benefits of B2C e-commerce, a lot of challenges must be solved. Perhaps, the most complicated and complex challenge of B2C $\mathrm{e}$-commerce, is REL processes management. The situation in REL is quite different in different markets of the world. Specific issues are faced in developing countries or countries that face certain internal problems for example, lack of infrastructure.

This study was done in the Lebanese and Syrian ecommerce companies in the electronic industry. It resulted in main eight factors that significantly impact REL performance, which are: management, incompetent employees, IT and technology, absence of return policy and procedures/guarantee, infrastructure, organizational structure and culture, customer services/satisfaction, and quality management. Therefore, for firms looking forward to improving REL performance, these eight factors should be taken into consideration. Moreover, this study proved the existence of a positive correlation between REL performance and increased companies' performance. This is another important benefit of having an effective REL performance in a company. Thus, the entire company could be affected by REL activities in a positive way if REL is implemented effectively. These results can be used by B2C e-commerce companies that are operating in developing countries, such as some countries in the Middle East that suffer from certain political conflicts and economic instabilities. Scientists in the REL field should emphasize more on the eight suggested factors and the research model built in this study for further analysis since they will create significant opportunities in developing countries where there is scarcity in terms of resources, technology, or experience in $\mathrm{B} 2 \mathrm{C}$ e-commerce.

The limitation of this research is the data collected in Syria because it was difficult to communicate with firms due to the war that happened in 2011, and which is still ongoing. This war has destroyed a lot of Syria's infrastructure, so e-commerce itself and REL management face many obstacles, and the situation is so dynamic that cant be considered finalized. Future research is in the Middle
Eastern countries, especially in the field of B2C e-commerce, and REL activities should be processed as they have the potential to grow.

\section{References}

Abebe, G. K.; Bahn, R. A.; Chalak, A.; Yehya, A. A. K. 2020. Drivers for the implementation of market-based food safety management systems: Evidence from Lebanon, Food Science \& Nutrition 8(2): 1082-1092.

https://doi.org/10.1002/fsn3.1394

Agarwal, V.; Govindan, K.; Darbari, J. D.; Jha, P. C. 2016. An optimization model for sustainable solutions towards implementation of reverse logistics under collaborative framework, International Journal of System Assurance Engineering and Management 7(4): 480-487.

https://doi.org/10.1007/s13198-016-0486-3

Agrawal, S.; Singh, R. K.; Murtaza, Q. 2016. Triple bottom line performance evaluation of reverse logistics, Competitiveness Review 26(3): 289-310.

https://doi.org/10.1108/CR-04-2015-0029

Al Majzoub, M.; Davidavičienè, V. 2019. Comparative analysis of reverse e-logistics' solution in Asia and Europe, in International Scientific Conference "Contemporary Issues in Business, Management and Economics Engineering 2019”, 9-10 May 2019, Vilnius, Lithuania, 890-899.

https://doi.org/10.3846/cibmee.2019.091

Al Majzoub, M.; Davidavičienè, V.; Meidutė-Kavaliauskienè, I. 2020. Measuring the impact of factors affecting reverse elogistics' performance in the electronic industry in Lebanon and Syria, Independent Journal of Management \& Production 11(6): 1969-1990. https://doi.org/10.14807/ijmp.v11i7.1254

Alamir, I.; Ayoubi, R. M.; Massoud, H.; Hallak, L. A. 2019. Transformational leadership, organizational justice and organizational outcomes: A study from the higher education sector in Syria, Leadership \& Organization Development Journal 40(7): 749-763. https://doi.org/10.1108/LODJ-01-2019-0033

Alsaeed, A.; Adams, C. 2015. E-service adoption in developing countries with instability status: the case of e-government in Syria, in ECEG 2015 - Proceedings of the 15th European Conference on e-Government, 18-19 June 2015, Portsmouth, UK. 376-385.

Anderson, P. 2018. Aleppo in Asia: mercantile networks between Syria, China and post-Soviet Eurasia since 1970, History and Anthropology 29(1): S67-S83.

https://doi.org/10.1080/02757206.2018.1513930

Ardila Gamboa, C. D.; Ballesteros Riveros, F. A. 2018. Data envelopment analysis to measure relative performance based on key indicators from a supply network with reverse logistics, INGE CUC 14(2): 137-146.

https://doi.org/10.17981/ingecuc.14.2.2018.13

Asian, S.; Pool, J. K.; Nazarpour, A.; Tabaeeian, R. A. 2019. On the importance of service performance and customer satisfaction in third-party logistics selection: an application of Kano model, Benchmarking: an International Journal 26(5): 1550-1564. https://doi.org/10.1108/BIJ-05-2018-0121

Bahn, R. A.; Abebe, G. K. 2017. Analysis of food retail patterns in urban, peri-urban and rural settings: a case study from Lebanon, Applied Geography 87: 28-44. https://doi.org/10.1016/j.apgeog.2017.07.010

Bai, C.; Sarkis, J. 2019. Integrating and extending data and decision tools for sustainable third-party reverse logistics provider selection, Computers \& Operations Research 110: 188-207. https://doi.org/10.1016/j.cor.2018.06.005 
Bal, A.; Satoglu, S. I. 2018. A goal programming model for sustainable reverse logistics operations planning and an application, Journal of Cleaner Production 201: 1081-1091. https://doi.org/10.1016/j.jclepro.2018.08.104

Batarfi, R.; Jaber, M. Y.; Aljazzar, S. M. 2017. A profit maximization for a reverse logistics dual-channel supply chain with a return policy, Computers \& Industrial Engineering 106: 58-82. https://doi.org/10.1016/j.cie.2017.01.024

Bouzon, M.; Spricigo, R.; Rodriguez, C. M. T.; De Queiroz, A. A.; Cauchick Miguel, P. A. 2015. Reverse logistics drivers: empirical evidence from a case study in an emerging economy, Production Planning \& Control: the Management of Operations 26(16): 1368-1385.

https://doi.org/10.1080/09537287.2015.1049239

Cannella, S.; Bruccoleri, M.; Framinan, J. M. 2016. Closed-loop supply chains: what reverse logistics factors influence performance?, International Journal of Production Economics 175: 35-49. https://doi.org/10.1016/j.ijpe.2016.01.012

Chen, L.; Li, W.; Zhai, H. 2016. The analysis of reverse logistics model in the e-commerce models, International Journal of Grid and Distributed Computing 9(9): 173-184. https://doi.org/10.14257/ijgdc.2016.9.9.15

Chileshe, N.; Rameezdeen, R.; Hosseini, M. R.; Martek, I.; Li, H. X.; Panjehbashi-Aghdam, P. 2018. Factors driving the implementation of reverse logistics: a quantified model for the construction industry, Waste Management 79: 48-57. https://doi.org/10.1016/j.wasman.2018.07.013

Chinda, T. 2017. Examination of factors influencing the successful implementation of reverse logistics in the construction industry: pilot study, Procedia Engineering 182: 99-105. https://doi.org/10.1016/j.proeng.2017.03.128

Choi, Y.; Mai, D. Q. 2018. The sustainable role of the e-trust in the B2C e-commerce of Vietnam, Sustainability 10(1): 291. https://doi.org/10.3390/su10010291

Cooper, A. L.; Huscroft, J. R.; Overstreet, R. E.; Hazen, B. T. 2016. Knowledge management for logistics service providers: the role of learning culture, Industrial Management \& Data Systems 116(3): 584-602.

https://doi.org/10.1108/IMDS-06-2015-0262

Da Silveira Guimarães, J. L.; Salomon, V. A. P. 2015. ANP applied to the evaluation of performance indicators of reverse logistics in footwear industry, Procedia Computer Science 55: 139-148. https://doi.org/10.1016/j.procs.2015.07.021

Daugherty, P. J.; Bolumole, Y.; Grawe, S. J. 2019. The new age of customer impatience: An agenda for reawakening logistics customer service research, International Journal of Physical Distribution \& Logistics Management 49(1): 4-32. https://doi.org/10.1108/IJPDLM-03-2018-0143

Davidavičienè, V.; Raudeliūnienè, J.; Tvaronavičienè, M.; Kaušinis, J. 2019. The importance of security aspects in consumer preferences in electronic environment, Journal of Security and Sustainability Issues: International Entrepreneurial Perspectives and Innovative Outcomes 8(3): 399-411.

El Rassi, M. A. B. 2020. Why one e-business adoption model won't fit all firm sizes: the case of Lebanon's e-service industry, The Electronic Journal of Information Systems in Developing Countries 86(5): e12135. https://doi.org/10.1002/isd2.12135

Eskandarpour, M.; Masehian, E.; Soltani, R.; Khosrojerdi, A. 2014. A reverse logistics network for recovery systems and a robust metaheuristic solution approach, The International Journal of Advanced Manufacturing Technology 74(9-12): 1393-1406. https://doi.org/10.1007/s00170-014-6045-7

Euchi, J.; Bouzidi, D.; Bouzid, Z. 2019. Structural analysis of acute success factors of performance of reverse logistics rela- tive to customer satisfaction, International Journal of Combinatorial Optimization Problems and Informatics 10(2): 39-56.

Ghasemzadeh, F.; Pishdar, M.; Antuchevičienė, J. 2017. Prioritization of petroleum supply chains' disruption management strategies using combined framework of BSC approach, fuzzy AHP and fuzzy Choquet integral operator, Journal of Business Economics and Management 18(5): 897-919.

https://doi.org/10.3846/16111699.2017.1380075

Govindan, K.; Bouzon, M. 2018. From a literature review to a multi-perspective framework for reverse logistics barriers and drivers, Journal of Cleaner Production 187: 318-337.

https://doi.org/10.1016/j.jclepro.2018.03.040

Han, H.; Trimi, S. 2018. A fuzzy TOPSIS method for performance evaluation of reverse logistics in social commerce platforms, Expert Systems with Applications 103: 133-145. https://doi.org/10.1016/j.eswa.2018.03.003

Huang, Y.-C.; Rahman, S.; Wu, Y.-C. J.; Huang, C.-J. 2015. Salient task environment, reverse logistics and performance, International Journal of Physical Distribution \& Logistics Management 45(9/10): 979-1006.

https://doi.org/10.1108/IJPDLM-08-2014-0182

Ibeh, K.; Kasem, L. 2011. The network perspective and the internationalization of small and medium sized software firms from Syria, Industrial Marketing Management 40(3): 358-367. https://doi.org/10.1016/j.indmarman.2010.08.004

Jianu, Iu.; Jianu, Io.; Turlea, C. 2017. Measuring the company's real performance by physical capital maintenance, Economic Computation and Economic Cybernetics Studies and Research 51(1): 37-57.

Keshavarz Ghorabaee, M.; Amiri, M., Olfat, L.; Khatami Firouzabadi, S. M. A. 2017. Designing a multi-product multi-period supply chain network with reverse logistics and multiple objectives under uncertainty, Technological and Economic Development of Economy 23(3): 520-548.

https://doi.org/10.3846/20294913.2017.1312630

Li, Y.-L.; Ying, C.-S.; Chin, K.-S.; Yang, H.-T.; Xu, J. 2018. Thirdparty reverse logistics provider selection approach based on hybrid-information MCDM and cumulative prospect theory, Journal of Cleaner Production 195: 573-584. https://doi.org/10.1016/j.jclepro.2018.05.213

Mahindroo, A.; Samalia, H. V.; Verma, P. 2018. Moderated influence of return frequency and resource commitment on information systems and reverse logistics strategic performance, International Journal of Productivity and Performance Management 67(3): 550-570.

https://doi.org/10.1108/IJPPM-05-2016-0101

Morgan, T. R.; Tokman, M.; Richey, R. G.; Defee, C. 2018. Resource commitment and sustainability: a reverse logistics performance process model, International Journal of Physical Distribution \& Logistics Management 48(2): 164-182. https://doi.org/10.1108/IJPDLM-02-2017-0068

Mouchawar, R. 2017. Souq.com's CEO on building an e-commerce powerhouse in the Middle East, Harvard Business Review (5): 35-38.

Mouselli, S.; Khalifa, B. 2017. Entrepreneurship in crisis: the determinants of Syrian students' entrepreneurial intentions, Business, Management and Education 15(2): 159-173. https://doi.org/10.3846/bme.2017.386

Nisar, T. M.; Prabhakar, G. 2017. What factors determine esatisfaction and consumer spending in e-commerce retailing?, Journal of Retailing and Consumer Services 39: 135-144. https://doi.org/10.1016/j.jretconser.2017.07.010

Ochocka, J. 2019. Mobile technologies in logistic customer service as a tool for winning customers' satisfaction, LogForum: 
Scientific Journal of Logistics 15(3): 403-411.

https://doi.org/http://doi.org/10.17270/J.LOG.2019.338

Pandian, G. R. S.; Abdul-Kader, W. 2017. Performance evaluation of reverse logistics enterprise - an agent-based simulation approach, International Journal of Sustainable Engineering 10(6): 384-398. https://doi.org/10.1080/19397038.2017.1370032

Panigrahi, S. K.; Kar, F. W.; Fen, T. A.; Hoe, L. K.; Wong, M. 2018. A strategic initiative for successful reverse logistics management in retail industry, Global Business Review 19(3): S151S175. https://doi.org/10.1177/0972150918758096

Pham, T. S. H.; Ahammad, M. F. 2017. Antecedents and consequences of online customer satisfaction: A holistic process perspective, Technological Forecasting and Social Change 124: 332-342. https://doi.org/10.1016/j.techfore.2017.04.003

Prakash, C.; Barua, M. K. 2015. Integration of AHP-TOPSIS method for prioritizing the solutions of reverse logistics adoption to overcome its barriers under fuzzy environment, Journal of Manufacturing Systems 37: 599-615. https://doi.org/10.1016/j.jmsy.2015.03.001

Pulansari, F.; Sukma Donoriyanto, D.; Masruroh, N. 2016. Customer's perception and expectation for reverse logistics implementation, Advances in Economics, Business and Management Research 15: 208-211.

https://doi.org/10.2991/gcbme-16.2016.38

Sangwan, K. S. 2017. Key activities, decision variables and performance indicators of reverse logistics, Procedia CIRP 61: 257-262. https://doi.org/10.1016/j.procir.2016.11.185

Sanyala, S.; Hisamb, M. W. 2019. Factors affecting customer satisfaction with ecommerce websites - an Omani perspective, in 2019 International Conference on Digitization (ICD), 18-19 November 2019, Sharjah, United Arab Emirates, 232-236. https://doi.org/10.1109/ICD47981.2019.9105780

Shaik, M. N.; Abdul-Kader, W. 2018. A hybrid multiple criteria decision making approach for measuring comprehensive performance of reverse logistics enterprises, Computers \& Industrial Engineering 123: 9-25.

https://doi.org/10.1016/j.cie.2018.06.007

Sirisawat, P.; Kiatcharoenpol, T. 2018. Fuzzy AHP-TOPSIS approaches to prioritizing solutions for reverse logistics barriers, Computers \& Industrial Engineering 117: 303-318. https://doi.org/10.1016/j.cie.2018.01.015

Skafi, M.; Yunis, M. M.; Zekri, A. 2020. Factors influencing SMEs' adoption of cloud computing services in lebanon: an empirical analysis using toe and contextual theory, IEEE Access 8: 79169-79181. https://doi.org/10.1109/ACCESS.2020.2987331

Soltany, Z.; Rostamzadeh, R.; Skrickij, V. 2018. A model to evaluate supply chain technology implementation influence on organizational performance, Transport 33(3): 779-792. https://doi.org/10.3846/transport.2018.5468

Sremac, S.; Stević, Ž.; Pamučar, D.; Arsić, M.; Matić, B. 2018. Evaluation of a third-party logistics (3PL) provider using a rough SWARA-WASPAS model based on a new rough Dombi aggregator, Symmetry 10(8): 305.

https://doi.org/10.3390/sym10080305

Sri Yogi, K. 2015. Performance evaluation of reverse logistics: a case of LPG agency, Cogent Business \& Management 2(1): 1063229. https://doi.org/10.1080/23311975.2015.1063229

Sudarto, S.; Takahashi, K.; Morikawa, K. 2017. Reprint “Efficient flexible long-term capacity planning for optimal sustainability dimensions performance of reverse logistics social responsibility: a system dynamics approach", International Journal of Production Economics 190: 45-59.

https://doi.org/10.1016/j.ijpe.2017.06.017
Sudarto, S.; Takahashi, K.; Morikawa, K.; Nagasawa, K. 2016. The impact of capacity planning on product lifecycle for performance on sustainability dimensions in reverse logistics social responsibility, Journal of Cleaner Production 133: 28-42. https://doi.org/10.1016/j.jclepro.2016.05.095

Sun, Q. 2017. Research on the influencing factors of reverse logistics carbon footprint under sustainable development, Environmental Science and Pollution Research 24(29): 2279022798. https://doi.org/10.1007/s11356-016-8140-9

Tan, Y.; Guo, C. 2019. Research on two-way logistics operation with uncertain recycling quality in government multi-policy environment, Sustainability 11(3): 882

https://doi.org/10.3390/su11030882

Tavengerwei, R. 2018. Using trade facilitation to assist MSMEs in e-commerce in developing countries, Journal of International Economic Law 21(2): 349-378.

https://doi.org/10.1093/jiel/jgy022

Tosarkani, B. M.; Amin, S. H. 2018. A multi-objective model to configure an electronic reverse logistics network and third party selection, Journal of Cleaner Production 198: 662-682. https://doi.org/10.1016/j.jclepro.2018.07.056

Tseng, S.-C.; Hung, S.-W. 2014. A strategic decision-making model considering the social costs of carbon dioxide emissions for sustainable supply chain management, Journal of Environmental Management 133: 315-322.

https://doi.org/10.1016/j.jenvman.2013.11.023

Vlachos, I. P. 2016. Reverse logistics capabilities and firm performance: the mediating role of business strategy, International Journal of Logistics Research and Applications: a Leading Journal of Supply Chain Management 19(5): 424-442.

https://doi.org/10.1080/13675567.2015.1115471

Wang, H.; Jiang, Z.; Zhang, H.; Wang, Y.; Yang, Y.; Li, Y. 2019. An integrated MCDM approach considering demands-matching for reverse logistics, Journal of Cleaner Production 208: 199210. https://doi.org/10.1016/j.jclepro.2018.10.131

Waqas, M.; Dong, Q.-L.; Ahmad, N.; Zhu, Y.; Nadeem, M. 2018. Critical barriers to implementation of reverse logistics in the manufacturing industry: a case study of a developing country, Sustainability 10(11): 4202.

https://doi.org/10.3390/su10114202

Xu, S. X.; Cheng, M.; Huang, G. Q. 2015. Efficient intermodal transportation auctions for B2B e-commerce logistics with transaction costs, Transportation Research Part B: Methodological 80: 322-337. https://doi.org/10.1016/j.trb.2015.07.022

Xu, Y.; Zhang, X.; Cao, J.; Chen, Y.; Ye, X. 2016. Collaboration and evolution of e-commerce and express delivery industry supply chain, Discrete Dynamics in Nature and Society 2016: 3452037. https://doi.org/10.1155/2016/3452037

Yadav, D. K.; Barve, A. 2015. Analysis of critical success factors of humanitarian supply chain: an application of interpretive structural modeling, International Journal of Disaster Risk Reduction 12: 213-225. https://doi.org/10.1016/j.ijdrr.2015.01.008

Yu, H.; Solvang, W. D. 2017. A carbon-constrained stochastic optimization model with augmented multi-criteria scenariobased risk-averse solution for reverse logistics network design under uncertainty, Journal of Cleaner Production 164: 12481267. https://doi.org/10.1016/j.jclepro.2017.07.066

Zaidan, E. 2017. Analysis of ICT usage patterns, benefits and barriers in tourism SMEs in the Middle Eastern countries: the case of Dubai in UAE, Journal of Vacation Marketing 23(3): 248-263. https://doi.org/10.1177/1356766716654515 